\title{
لمحة عن تاريخ دخول الإسلام إلى سومطرة
}

\author{
Ahmad Asri Lubis \\ Universiti Islam Sultan Sharif Ali, Brunei Darussalam \\ asrilubis@yahoo.com
}

\begin{abstract}
الملتخص
إن المسلمين بأرخبيل الملايو يربو عددهم عن إخواهم بالأقطار العربية بأسرها؛ ومن ثم فإن دراسة ما له صلة بالإسلام بالأرخبيل - على كثرةا وتتابعها- لجديرة بالتناول والعناية، وفي مقدمتها تاريخ أول مجيء الإسلام إلى هذه المنطقة. ولا سيما أن هذه الدراسة مبنية على مصادر ومراجع أولية التى تركها حلة رسالة العلم الأجلاء وأصحاب الدراسات قديما وحديثا على اختلاف مشاربهم ومذاهبهم، فهذا هو الذي يستهدف إليه هذا المسعى المتواضع تحت عنوان المحة عن تاريخ دخول الإسلام إلى سومطرة إندونيسياه وبالأحرى تاريخ أول دخول الإسلام إلى منطقة أتشيه المعروفة بسومطرة، فقد توصلت الدراسات وتعاضدت البراهين على أن نور الدين الإسلامي قد انبثق لأول مرة بجزيرة سومطرة في القرن

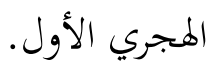

الكلمات المفتاحية: تاريخ، الإسلام، سومطرة
\end{abstract}

\begin{abstract}
The Muslims in the Malay Archipelago are more than their brothers in the entire Arab countries. Thus, studying what is related to Islam in the Archipelago - and its many and follow-up - is worthy of taking care and care, foremost of which is the history of the first coming of Islam to this region. Especially that this study is based on the sources and references to the initial left by the campaign of the message of science and scholars and scholars of old and recent differences in their denominations and denominations, this is aimed at this modest endeavor under the title «an overview of the history of the entry of Islam to Sumatra Indonesia» and rather the date of the first entry of Islam To the Aceh region of Sumatra, studies have come together and evidence has been consolidated that Nur al-Din al-Islami originated for the first time on the island of Sumatra in the first century AH.
\end{abstract}

Keywords: History, Islam, Sumatra

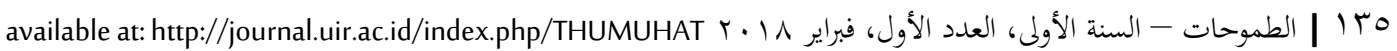




\section{إندونيسيا في التاريخ القديم}

لم يعرف اسم (إندونيسيا) من حيث التسمية إلا في منتصف القرن التاسع عشر؛ إذ يرجع تاريخ استعمال هذه

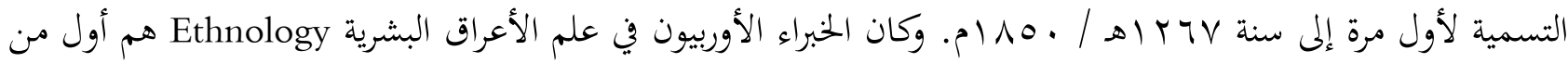

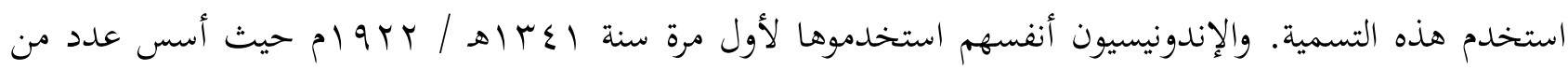
الطلبة الإندونسيين الدارسين بـ(هولندة) جبهة تنادي باستقلال البلاد عن الاستعمار. وكان اسم هذه الجبهة "التجمع . Indonesische Vreeniging "'الإندونيسي ولما كان عرب جنوبي الجزيرة العربية قد عرفوا البحارة منذ حوالي ألف سنة قبل الإسلام '، ومياه أرخبيل الملايو كانت محرا بتحاريا للتجار الشرقيين - بمن فيهم العرب والصينيين والهنود - منذ ما قبل الميلادّ، مرورا بعهد الأسرة الساسانية ، حتى القرن الثالث الهجريْ (التاسع الميلادي) ، وما كان الأمر كذلك، فمن الطبيعي أن العرب قد تعرفوا

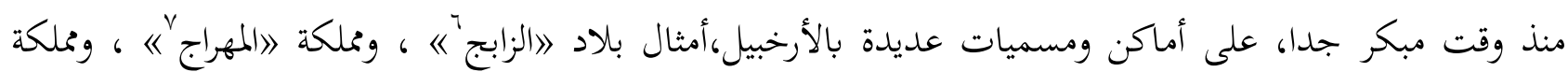

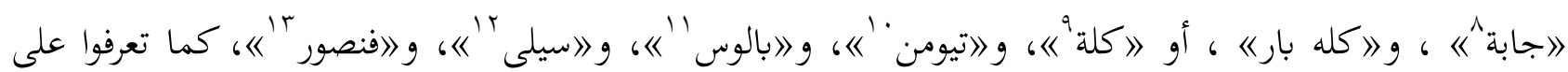
》اسومطرة و 》جاوة|《يما بعد، علما أن جل هذه المسميات ظلت باقية حتى الآن، مع تغيير يسير في بعضها.

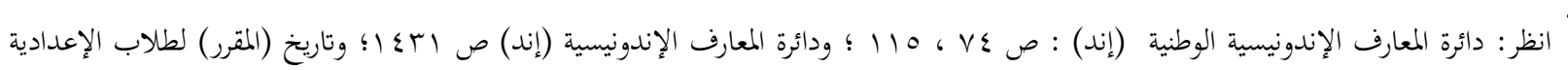

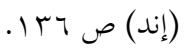

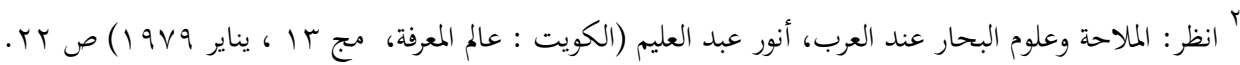

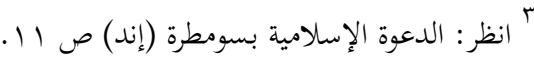

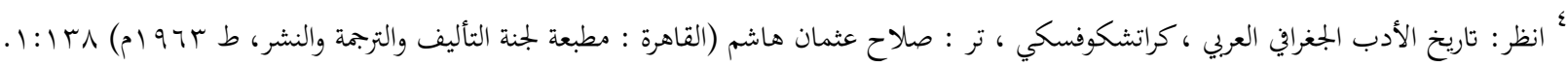

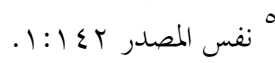

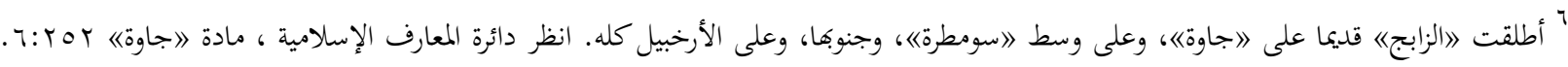

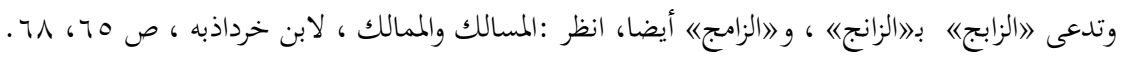

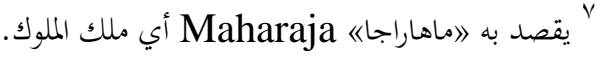

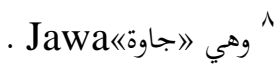

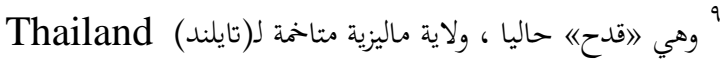
' ' ل جزيرة ماليزية تقع شرقي شبه الجزيرة الماليزية. "أي \باروس" Barus وهي بلدة في الساحل الغربي لشمال 》سومطرة)، وكانت أهم الموانيء بالأرخبيل؛ ومن ثخ كانت أول منطقة دخلها الإسلام بزيزة سومطرة ، كما سيأتي.

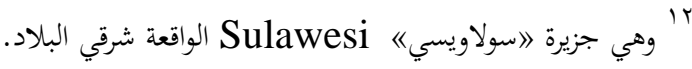
كا بلدة في ضاحية باروس.

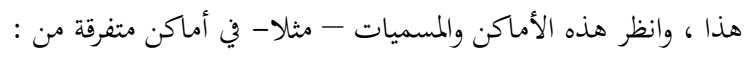

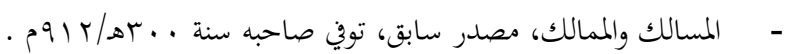

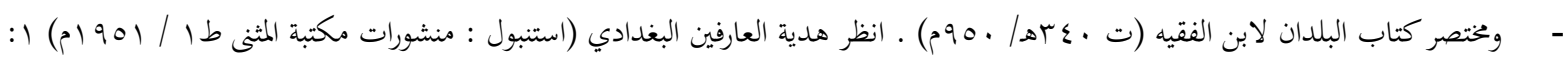

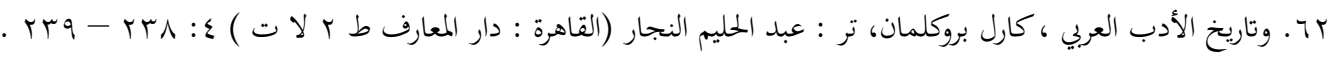

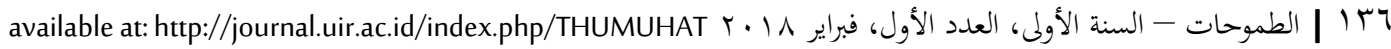


وفي الماضي القريب عرفت إندونيسيا بمسميات أخرى، أمثال: 》أنسلنده، وأرخبيل الملايو، والأرخبيل الهندي،

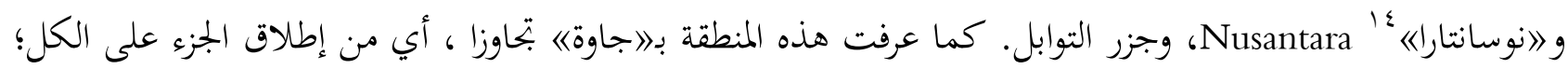

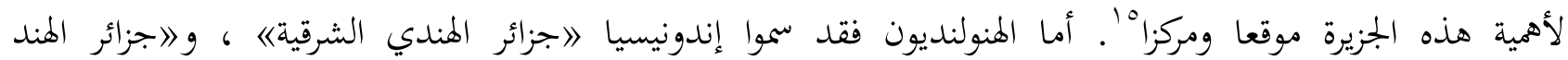
الهولندية《.

ولم يعرف على الوجه التحديد تاريخ بداية سكان هذه الجزر؛ غير أن الأثريين اكتشفوا لأول مرة جزءا متحجرا

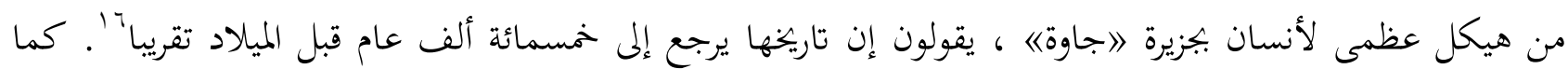

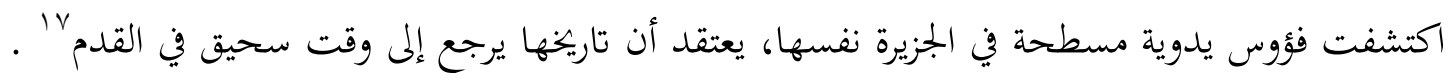

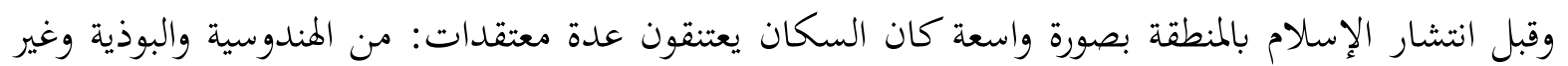
ذلك. وقد بلغ ترسخ هذه الديانات غايته؛ بدليل قيام حكومات مبنية على اساس ديني بالمنطقة، مثل الأمبراطروريتين

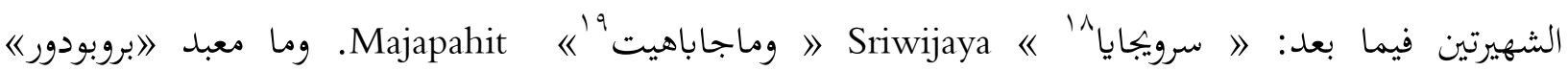
Brobudur

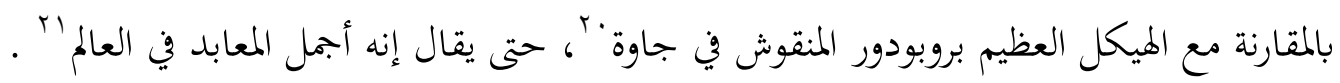

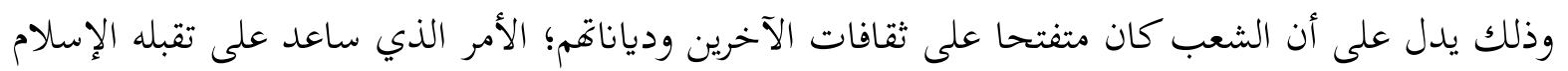
- إضافة إلى عوامل أخرى - كما سيأتي بياها .

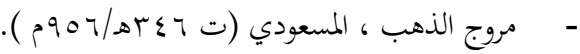

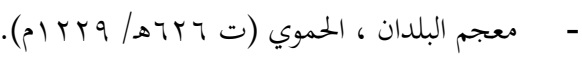

$$
\begin{aligned}
& \text { - الملاحة وعلوم البحار عند العرب ، مصدر سابق. }
\end{aligned}
$$

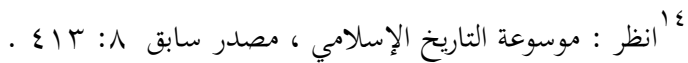

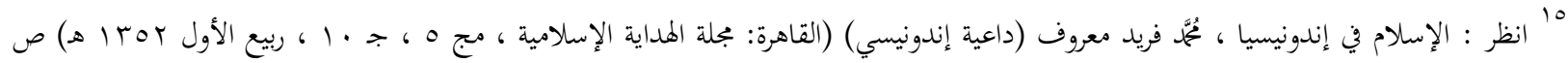$$
\text { . OH人 }
$$

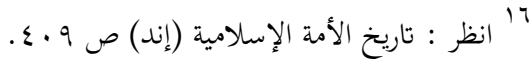

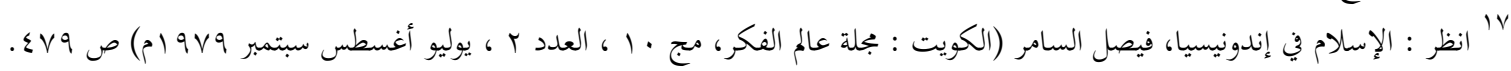

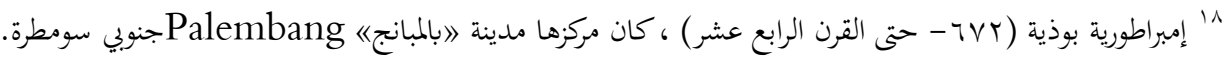

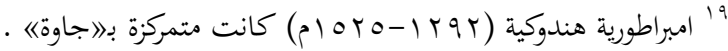

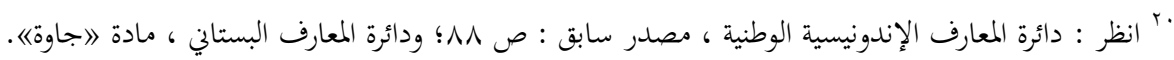

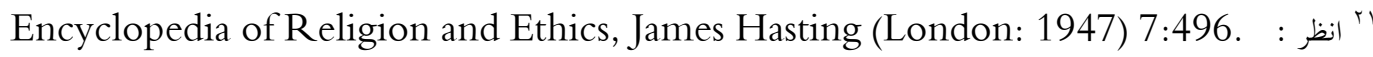

$$
\text { | وتاريخ الحضارات العام (القرون الوسطى)، إدوارد بروي وآخرون، تر: يوسف أسعد داغر وفريد داغر (بيروت: منشورات عويدات طا }
$$




\section{العلاقة بين الملايو والعرب وأوربا قديما.}

تقدم أن مياه الملايو كان يمر بها خط الملاحة البحرية من بلاد العرب إلى الصين، وبالعكس. كما تقدم أن المان

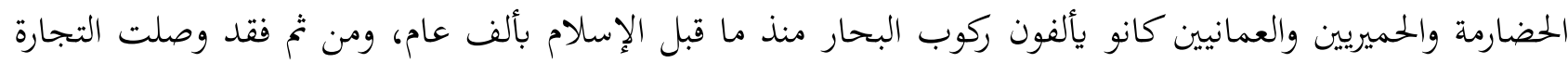

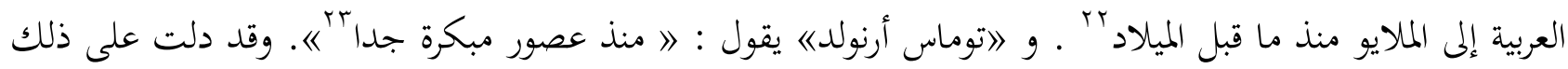

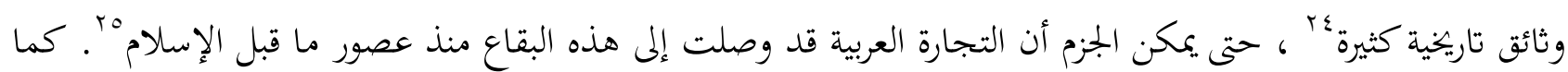

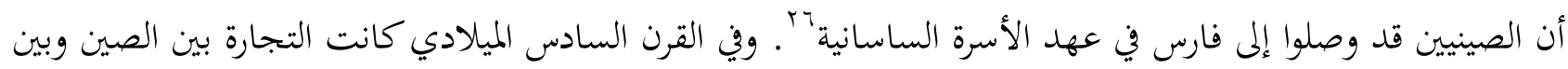

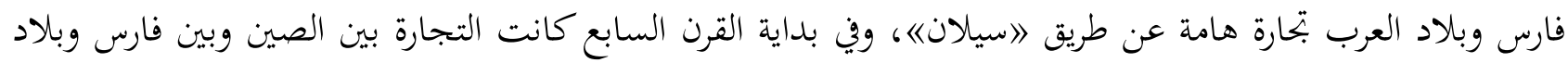

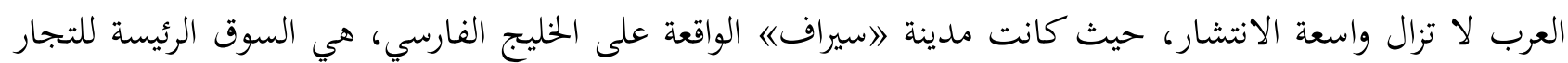
الصنيين '. و ولا يستبعد وصول التجار الملايويين إلى هذه المدينة التجارية في الفترة المذكورة أيضا.

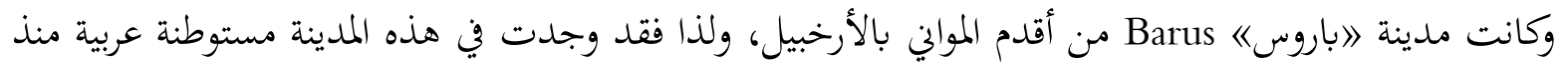

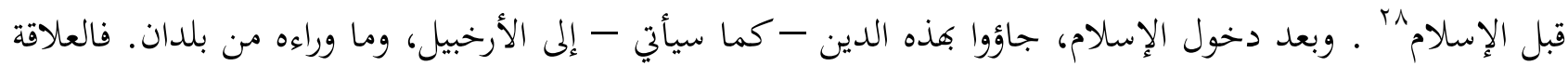

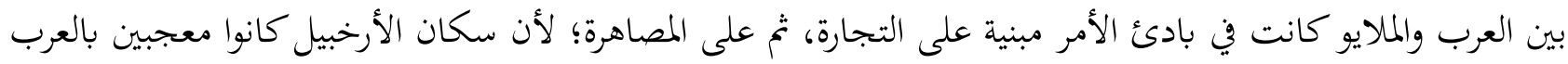

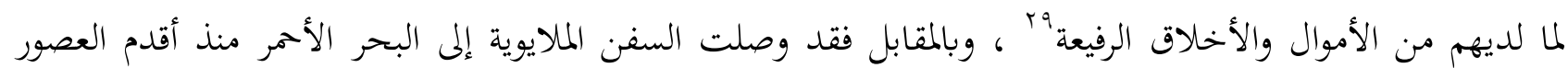
أيضا.ب.

وقد دل ما تقدم على قدم الارتباط ووثوقه بين سكان أرخبيل الملايو والعرب، الأمر الذي يختلف عن سكان

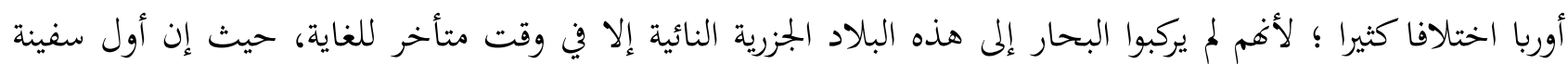

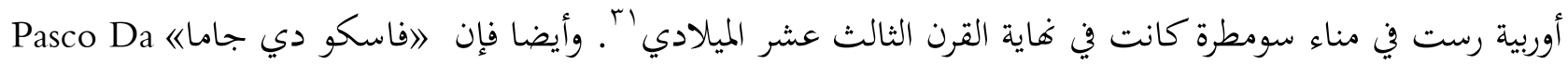
Gama

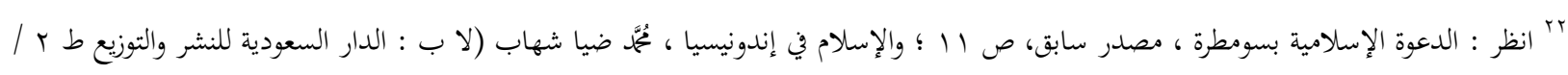

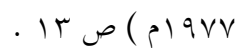

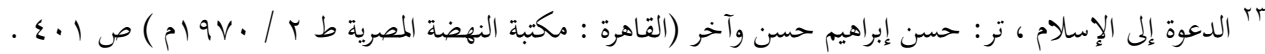

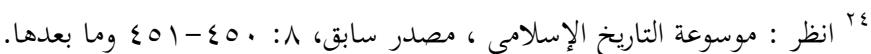

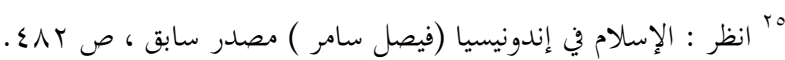

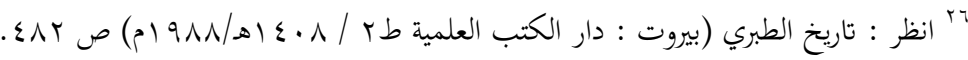

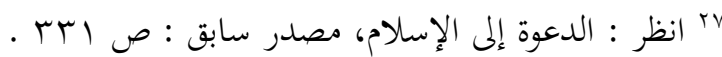

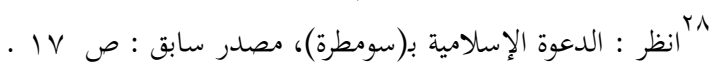

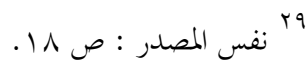

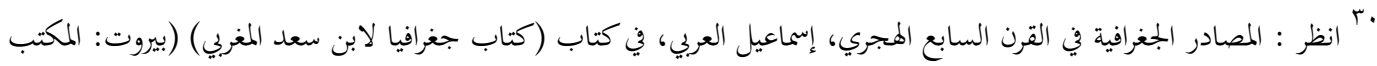

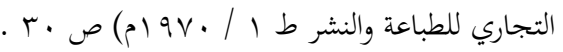

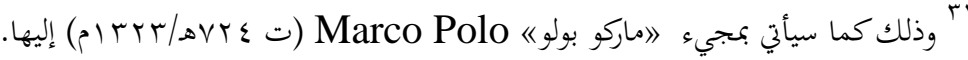

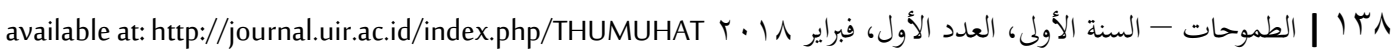




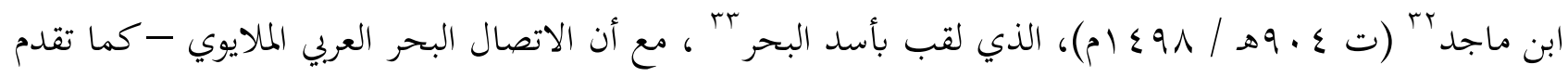
- قد بدأ قبل الميلاد أو قبل الإسلام على الأقل .

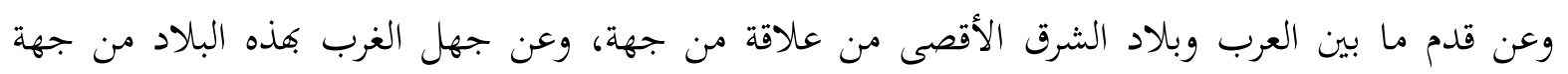

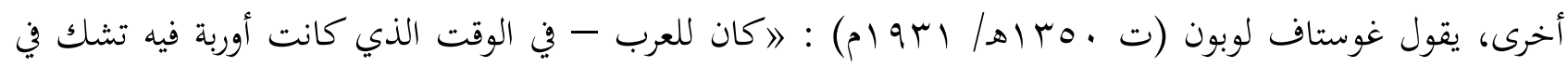

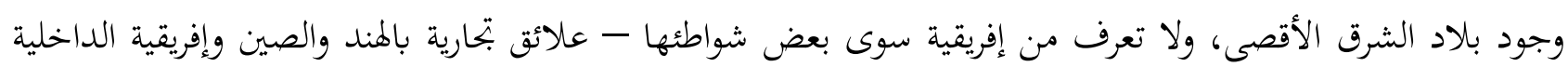

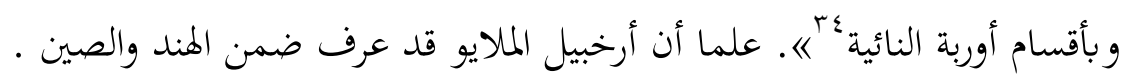

\section{دخول الإسلام إلى سومطرة}

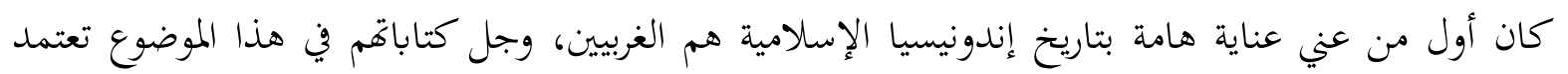

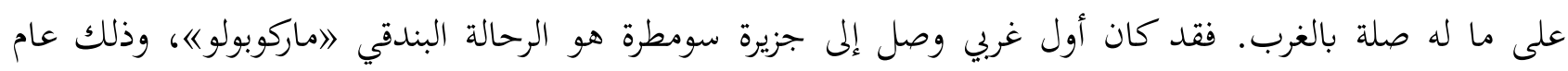

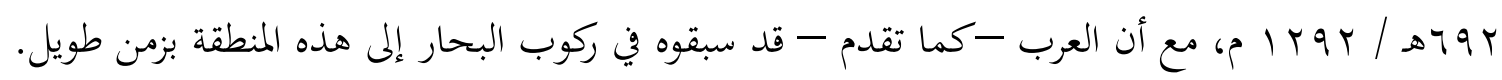

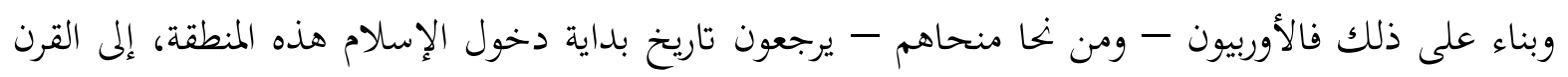

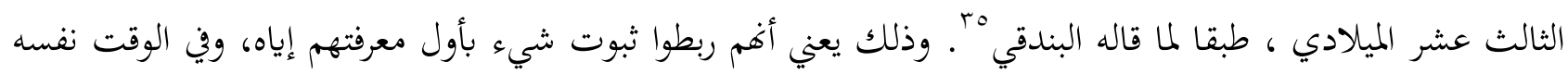

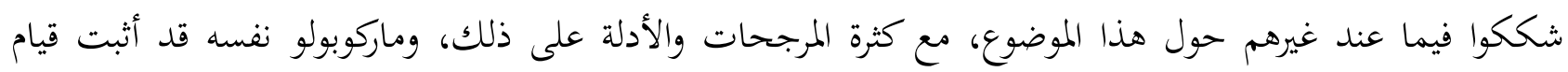

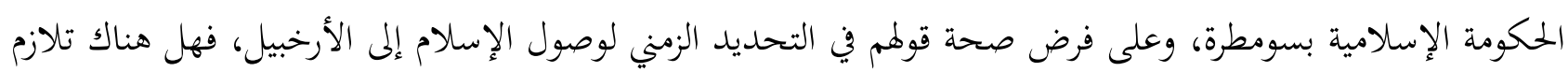

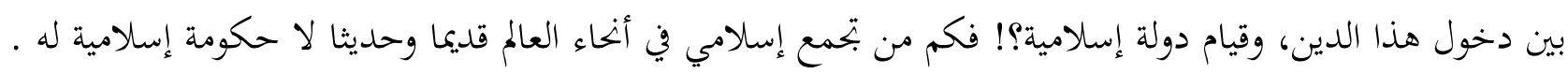

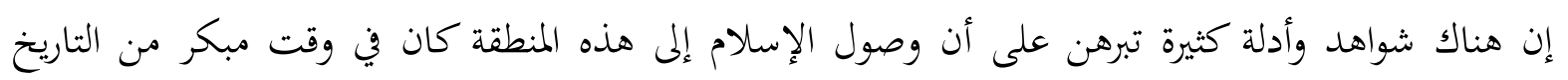

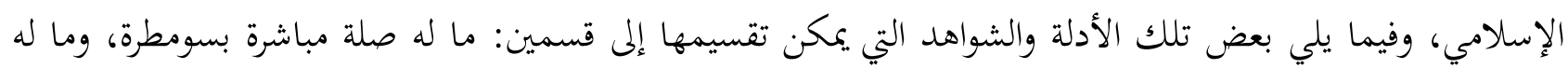

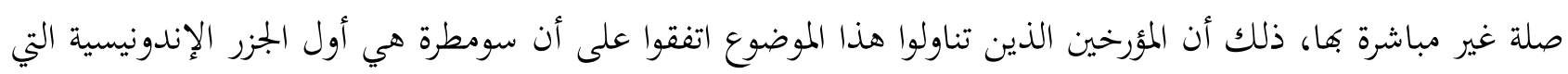
دخلها الإسلام.

ويكفي إيراد ثلاثة أدلة لكل قسم، تفاديا للإطالة، فالقسم الأول :

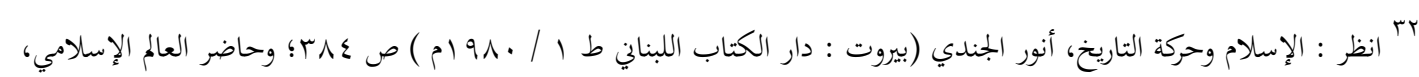

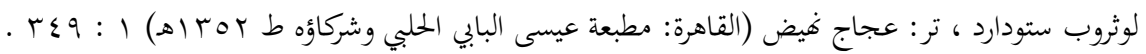

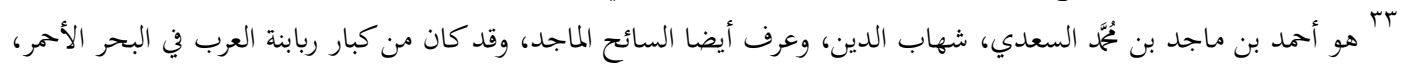

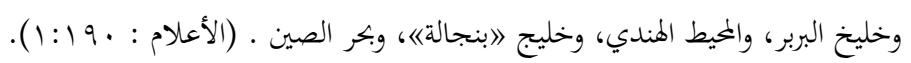

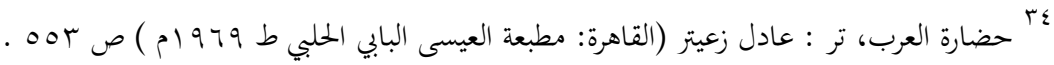

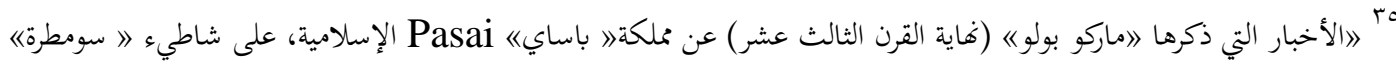

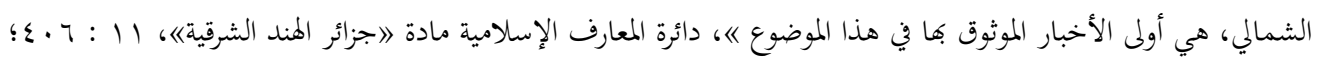

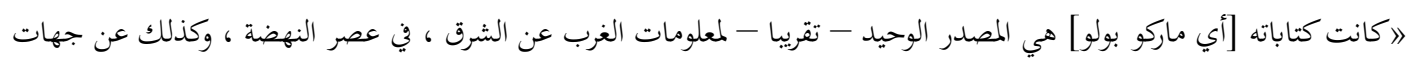

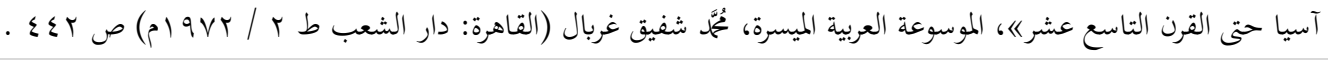

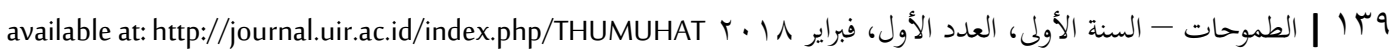


عرف من الدلائل التاريخية أنه توجد أحياء للعرب في الساحل الغربي لاسومطرة/ منذ منتصف القرن الأول

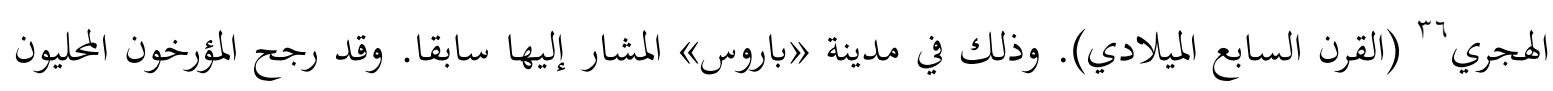

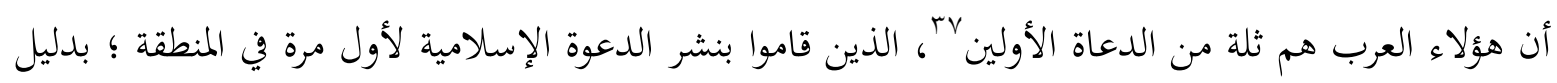

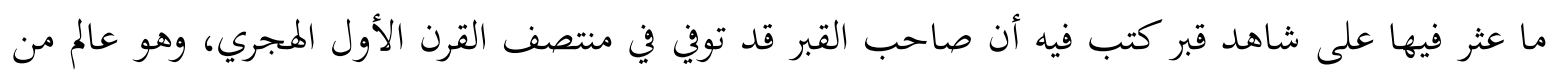

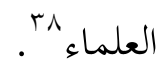

برز في تاريخ الدعوة الإسلامية في البلاد العديد من العلماء الأجلاء، وفي مقدمتهم الشيخ لانور الدين

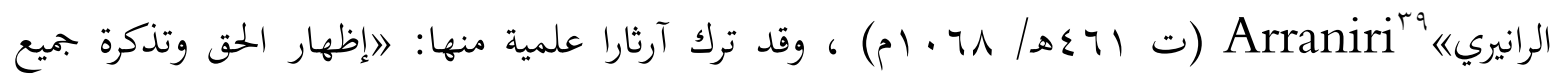

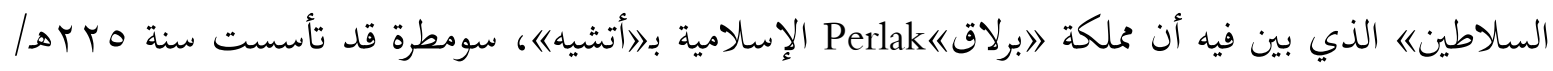

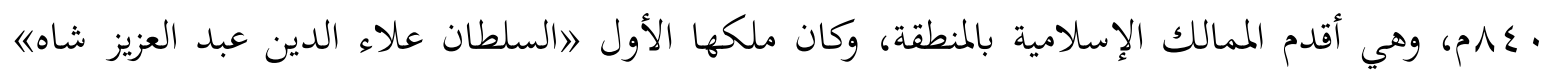

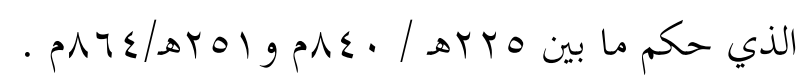

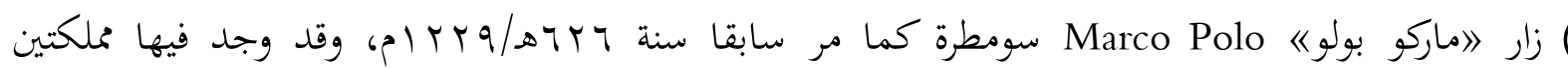

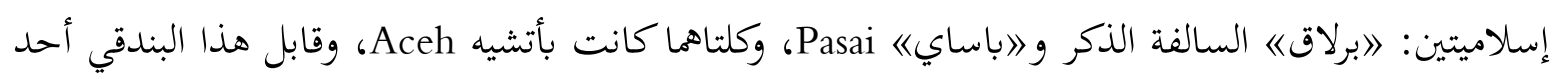

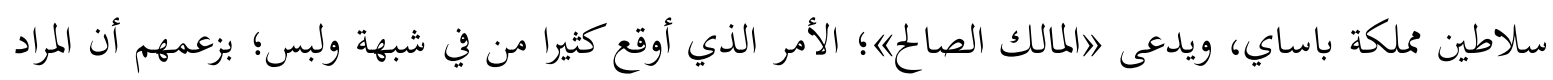

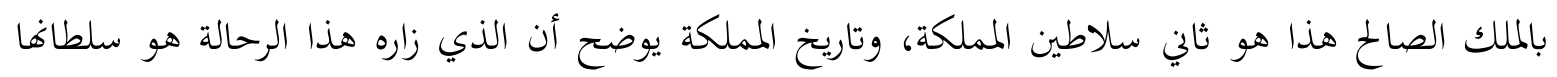

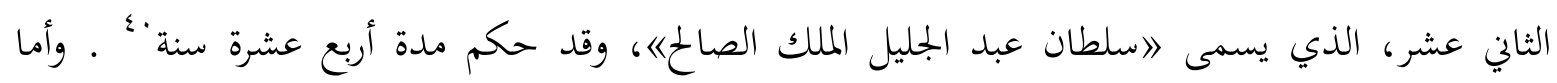

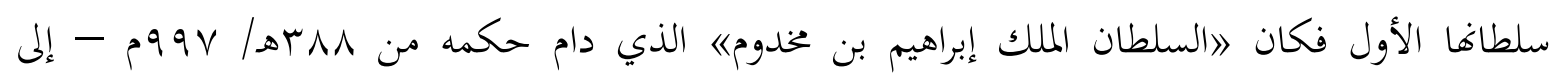

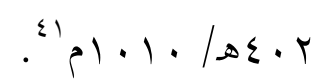
وأما القسم الثاني من الأدلة - وهي التي لها علاقة غير مباشرة بالسومطرة| فهو : "rr انظر : الدعوة إلى الإسلام ، مصدر سابق : ص r. ع؛ وتاريخ الإسلام في إندونيسيا : النشأة والتطور (إند) ص عابr.

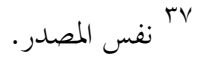

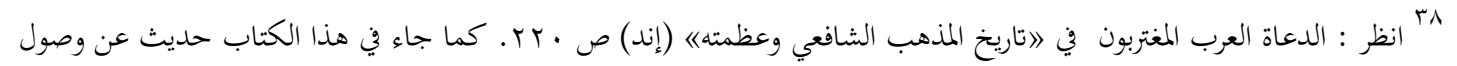

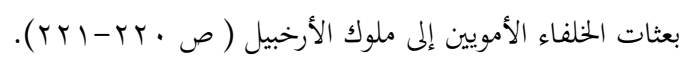

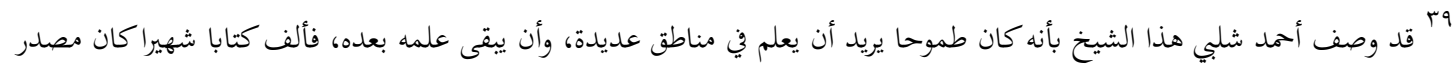

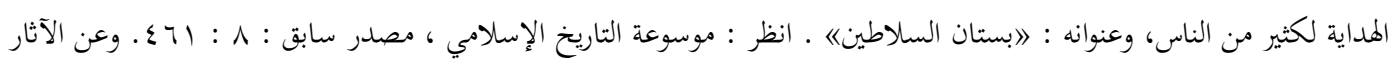

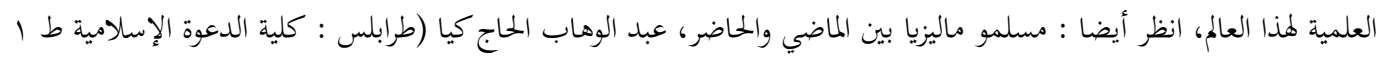

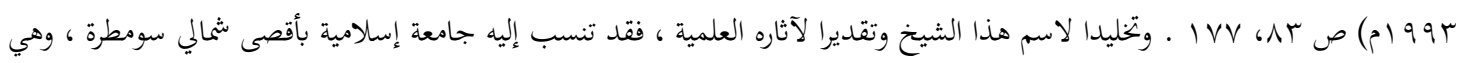

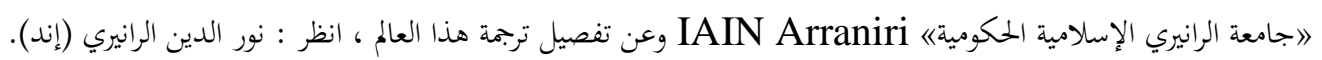

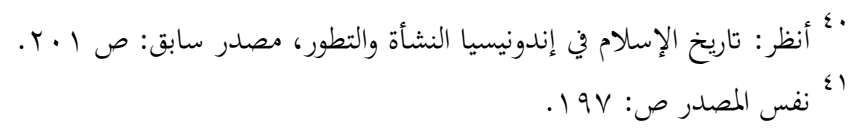

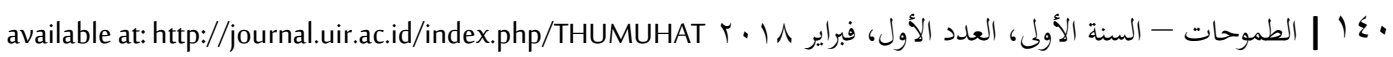




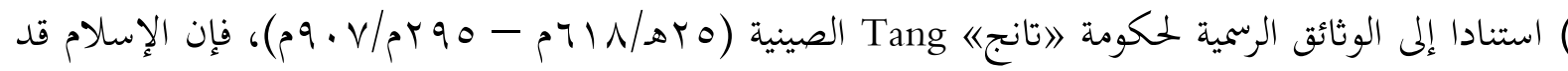

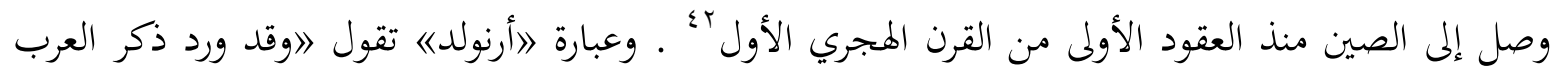
لأول مرة في التوارخ الصينية في ذلك الوقت الذي ابتدأ فيه حكم دولة تانج" بـ. وقد توطدت الصلات

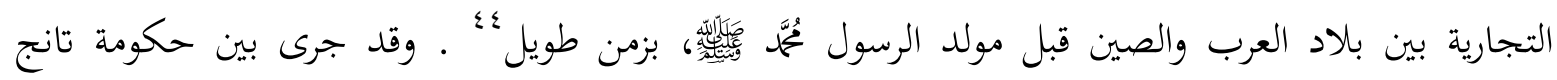

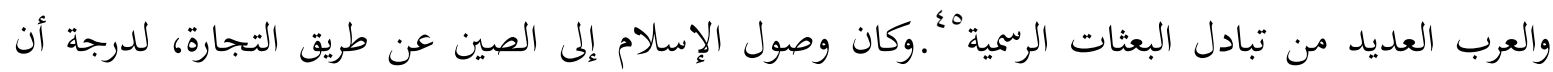
التجار العرب والفرس قد سيطروا على قسط كبير من النشاط التجاري بمدينة 》كانتون《 Canton الصينية الساحلية التجارية، التي عرفت سابقا باكانفو《 Khanfu، وذلك من النصف الثاني في القرن الثامن بـ حتى منتصف القرن التاسع الميلادي؛ \؛ ، حيت احترقت فيها المخازن التجارية العربية والفارسية، وغيرها في كانتون؛ من جراء الحروب والفتن الداخلية. وبالمقابل فإن السفن الصينية - كما تقدم - قد وصلت إلى الخليج العربي منذ ما قبل الإسلام. وقد سبقت الإشارة إلى أن الملاحة البحرية بين بلاد العرب والصين كانت تمر بمياه

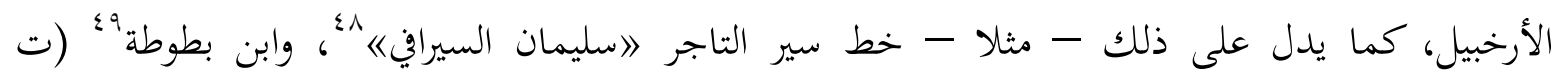

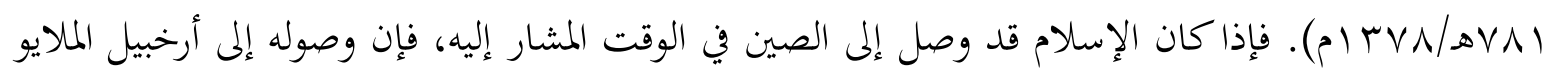
كان بالضرورة قبل ذلك .

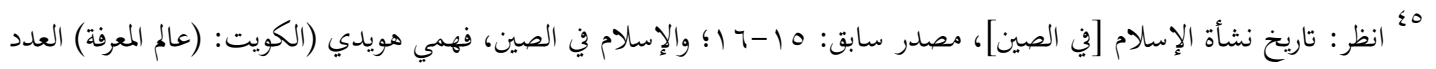

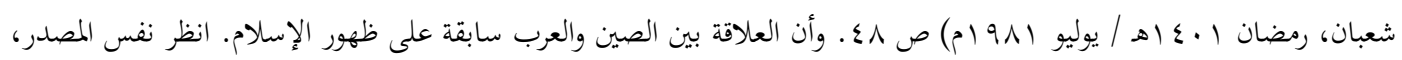
نقالا عن مصدر صيني.

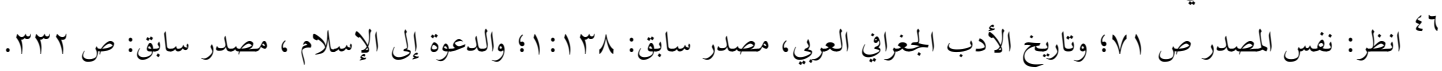

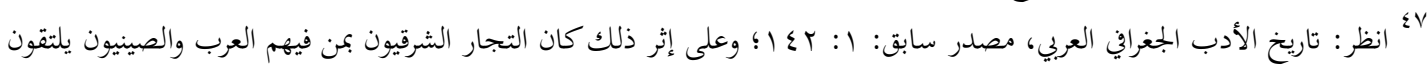

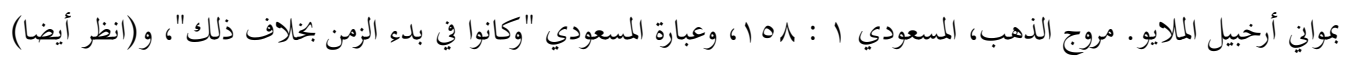

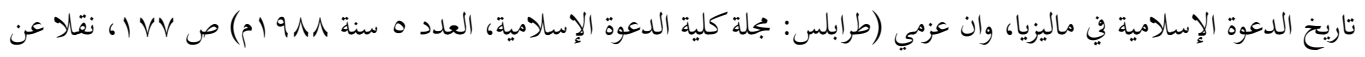

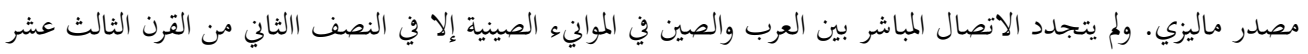

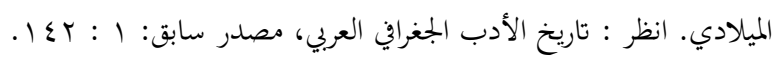
سافر مرارا للتجارة من "سيراف"، فمسقط، إلى الصين مرورا بأرخبيل الملايو، وكانت الرحلة من مسقط إلى الصين تستغرق الرئ أربعة

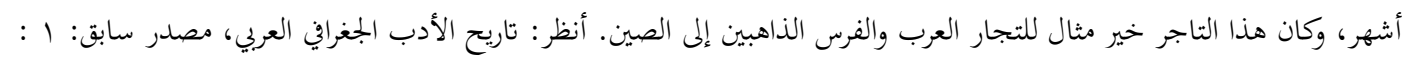

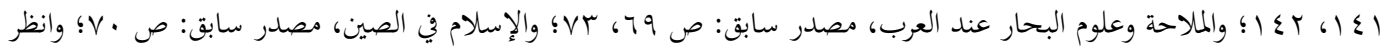
تاريخ الأدب العربي، مصدر سابق: ع : مبr. ولم يرد في هذه المصادر تاريخ وفاة هذا التاجر.

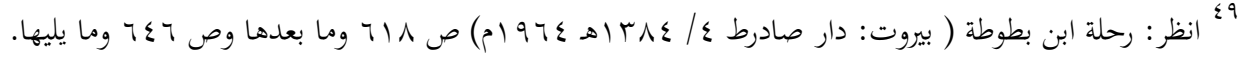

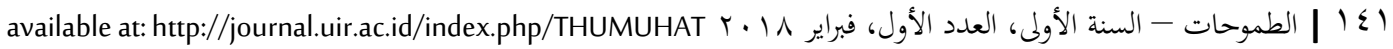


(r) أن جماعة من العلويين قد استوطنوا منذ أيام الأمويين في جزية 》سولاويسي) Sulawesi المتقدم ذكرها المسماة

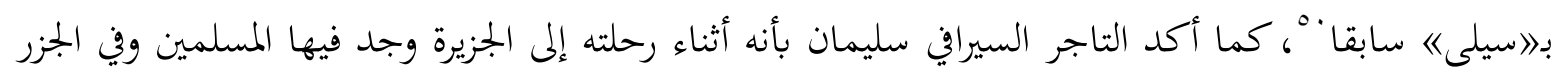

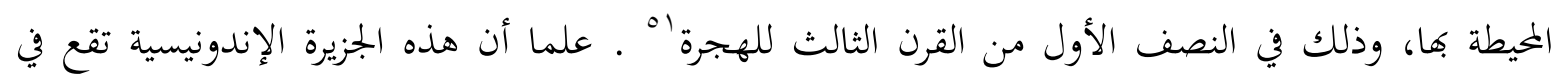
أقصى الشرق لأندونيسيا، أي قرب الحدود الإندونيسية الفلبينية حاليا، فوصول هؤلاء إلى هناك لم يتم إلا عن طريق 》سومطرة|《. (ץ) وما اتفق عليه في تاريخ إندونيسيا الإسلامية وصول الإسلام إلى جزيرة 》جاوة) عن طريق سومطرة في القرن العاشر الميلادي، وقد عثر على قبر في قرية تدعى 》ليران《 قeran قبر 》جيرسيك《Gersik شرقي جاوة، وقد كتب على القبر بالعربية أنه لسيدة اسمها 》استى فاطمة بنت ميمون بن القاهر بالله) توفيت سنة or $111 \cdot 10290$ وهذه هي أهم الشواهد والأدلة في هذا الموضوع، وهناك أدلة أخرى أشار إليها بعض الباحثين، ولا ضرورة لسردها هنا خشية الإطالة . إن المؤرخين المحليين لمج يهتموا بهذا الجانب بصورة جماعية إلا بعد ما حرر الإندونسيون بلادهم من ربقة الاستعمار؛ إذ كان شغلهم الشاغل في عهد الاستعمار هو التخلص من السيطرة الأجنبية، وعدم الركون إلى سلطان الاستعمار الغربي النصرائ. وما أن أحسوا بالحرية في عهد الاستقلال حتى بدأوا في إصلاح وطنهم وبنائه. فمن إنجازاهم الإصلاحية دارستهم لكل ما نالته أيدي الاستعمار من تاريخ إندونيسيا عامة، وتاريخها الإسلامي خاصة، دراسة نزيهة مدعمة بوثائق تاريخية، ودلائل منطقية، تصحح بها مفاهيم محرفة، ابتدعها المستعمرون الذين احتلوا البلاد أكثر من ثلاثة قرون، كما قام المؤرخون المحليون بتنظيم لقاءات علمية تتمثل في عقد ندوات علمية في أوقات مختلفة، وفي أماكن متفرقة من جزية 》اسومطرة|؛ لإثبات أن هذه الجزيرة هي أولى الجزر الإندونيسية التي وصلها الإسلام كما تقدمت الإشارة إليه . وفيما يلي بيان خختصر بالندوات والأماكن والأزمنة التي عقدت فيها، وما توصلت إليه من نتائج:-

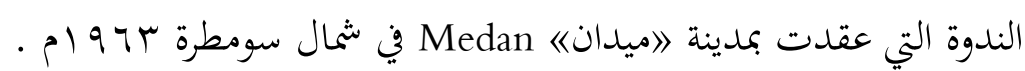
إباندا أتشيه $9 \vee \wedge$ Banda Aceh

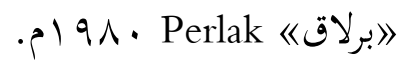

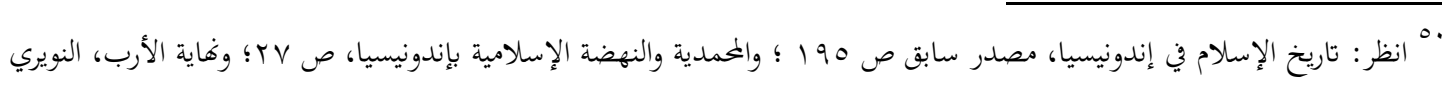

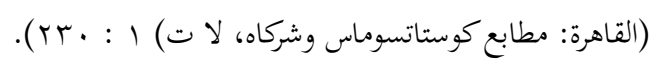

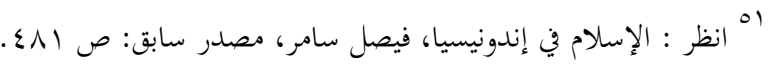

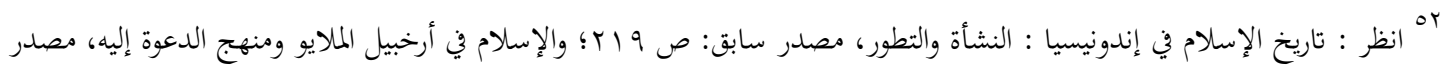
سابق: ص 9 §.

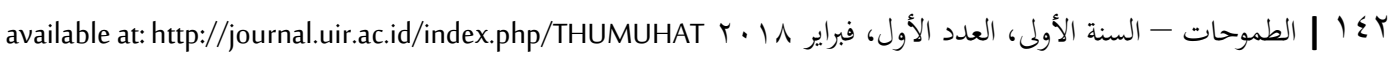




\section{•}

وتقع المدن الثلاث الأخيرة بمحافظة أتشيه Aceh في أقصى الشمال لجزيرة سومطرة. ومما جاء في نتائج الندوة الأولى ما يلي:

تبين من الدلائل والمصادر التي عرضت أن الإسلام قد دخل إندونيسيا لأول مرة في القرن الأول الهجري، أي

$$
\text { فيما بين القرنين السابع والثامن الميلاديين، ومن بلاد العرب مباشرة. }
$$

أن أول منطقة دخلها الإسلام هو السواحل الغربية لشمالي 》سومطرة《 ، وأنه بعد أن تكون المجتمع الإسلامي فيها وبعد أن تحصل على النفوذ السياسي، قامت المملكة الإسلامية الأولى في 》أتشيه|ه. أن بعض الدعاة الأولين كانوا من التجار، وأن الدعوة الإسلامية كانت سلمية، كما أن الإندونيسيين أنفسهم

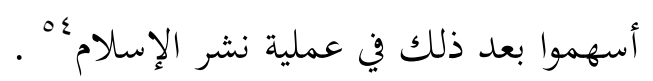

هذا، وقد أكد سائر الندوات نتائج الندوة الأولى، موضحة عدم الربط والتلازم بين دخول الإسلام وقيام المملكة

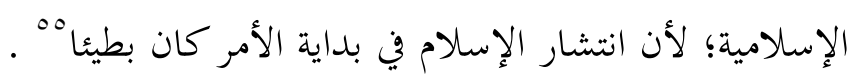
فلو تم الربط بين ما تقدم من قدم العلاقة بين العرب والملايو وتوطدها، وبين تعاضد الأدلة المرجحة على أن وصول الإسلام كان في وقت مبكر "ه، إضافة إلى ما توصلت إليها تلك الندوات ولقاءات مماثلة لها في أماكن مناسبات أخرى من نتائج، لتبين أن كل ذلك يؤيد بعضه بعضا، وأن أقوال المستشرقين وما سلك طريقهم - في هذا الأمر - باتت مرجوحة ، وأن استنتاجات مؤرخي الأرخبيل أصبحت راجحة. إن المستشرقين - وهم في محاولتهم إبعاد مسلمي أرخبيل الملايو عن أرض النبوة، ينبوع الإسلام الأصيل، إضافة إلى ما سبقت الإشارة إليه من رأيهم في التحديد الزمني لدخول الإسلام إلى هذه المنطقة - يقولون إن هذا الدين لم يأت إلى أرض الملايو من بلاد العرب مباشرة. وقد اختلفوا فيما بينهم في التحديد المكاني الذي التحه منه الإسلام إلى

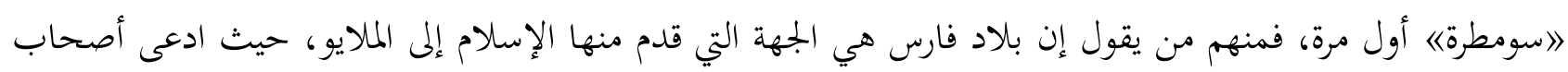
هذا الرأي بأن كلمة 》فاساي《 Pasai التي أطلقت كما تقدم على مملكة إسلامية بهاسومطرة《 هي فارسية الأصل، أي

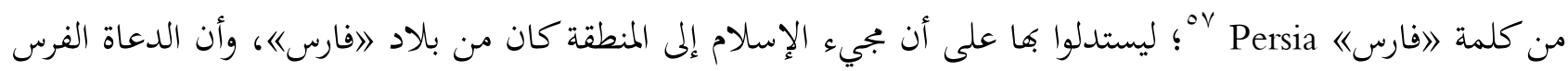
هم الذين نشروا الإسلام بسومطرة، مع أن قيام مملكة 》برلاق《 المتقدم ذكرها قد سبق قيام مملكة 》باساي《 بأكثر من

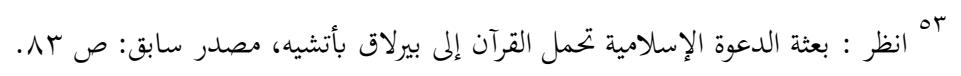

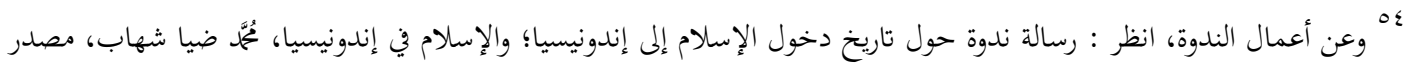

$$
\text { سابق: ص } 9 \text { وما بعدها. }
$$

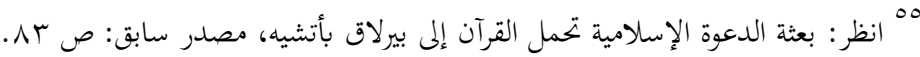

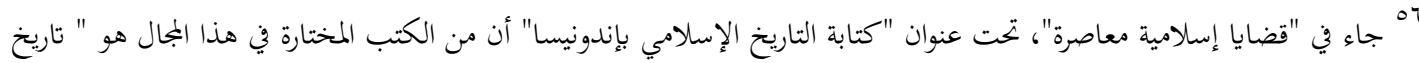

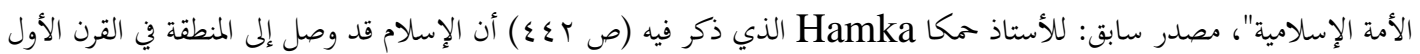


قرن ونصف، بل هناك من المستشرقين من يذهب إلى أن مملكة 》باساي《هذها هذه أسست قبل بجيء الإسلام إلى الأرخبيل

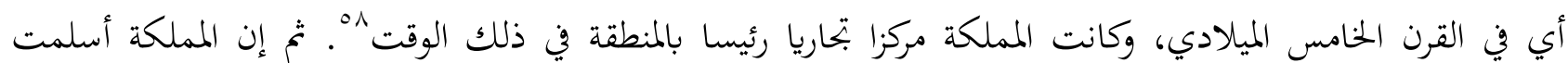

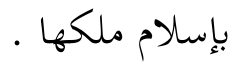
وأما سر تسمية هذه المملكة هذذا الاسم 》باساي《 المشتق أصلا من 》باسى Pasi)، فإن هذه الكلمة في لغة

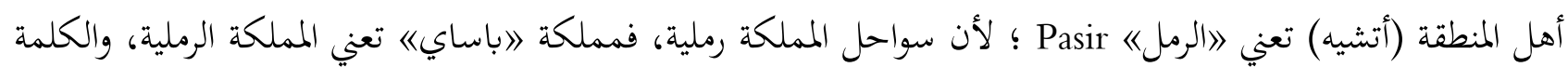

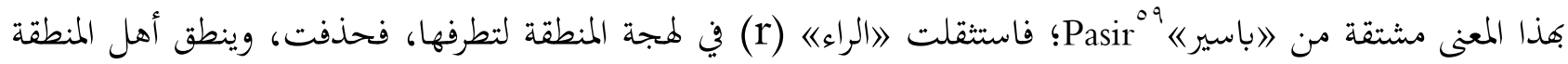

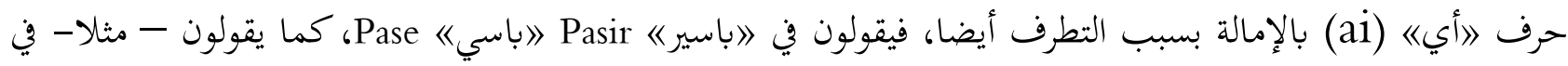

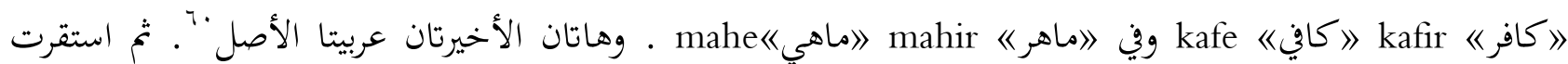

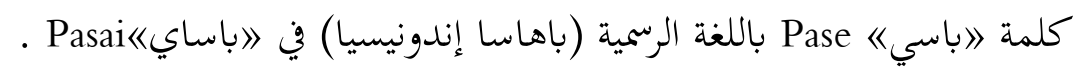

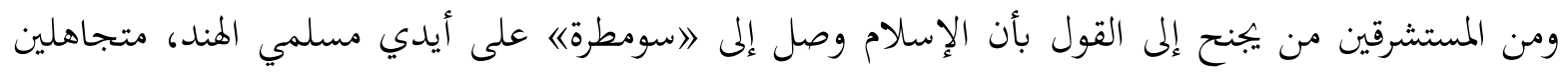

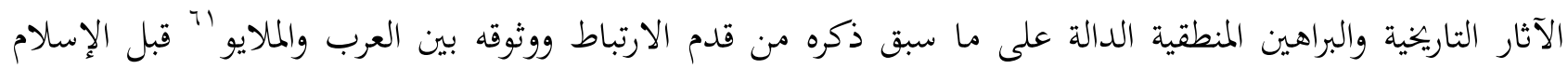
وبعده. وعند مراجعة أقوال هؤلاء المستشرقين حول هذا الموضوع يتضح التضارب الكثير فيها، حتى إن المستشرق الواحد

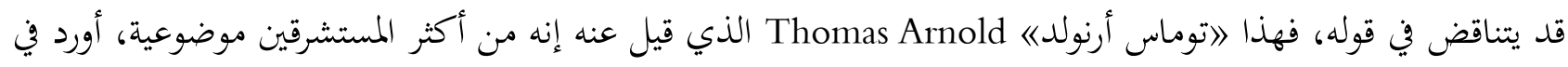

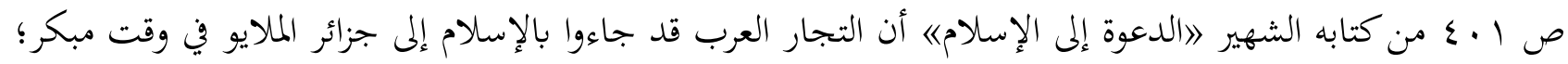

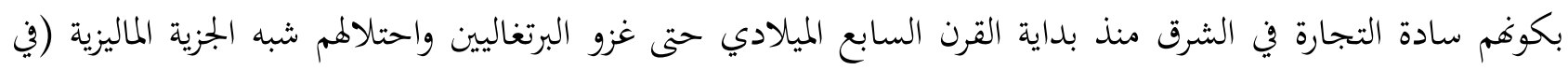

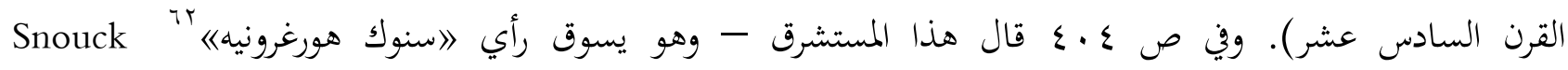

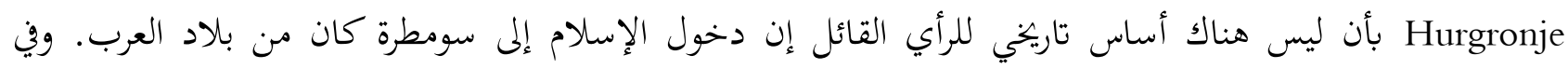

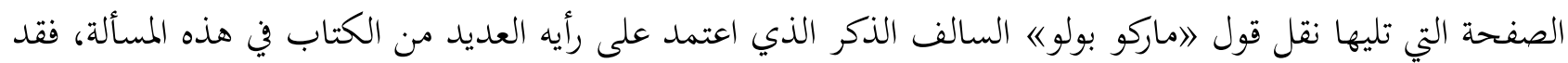

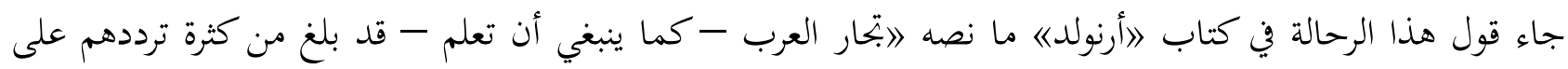

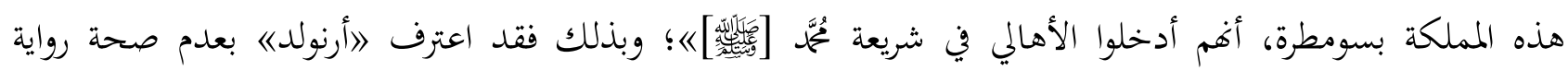

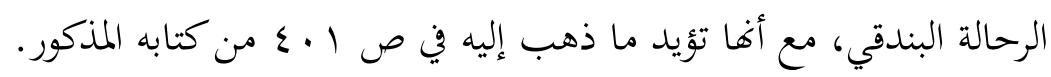

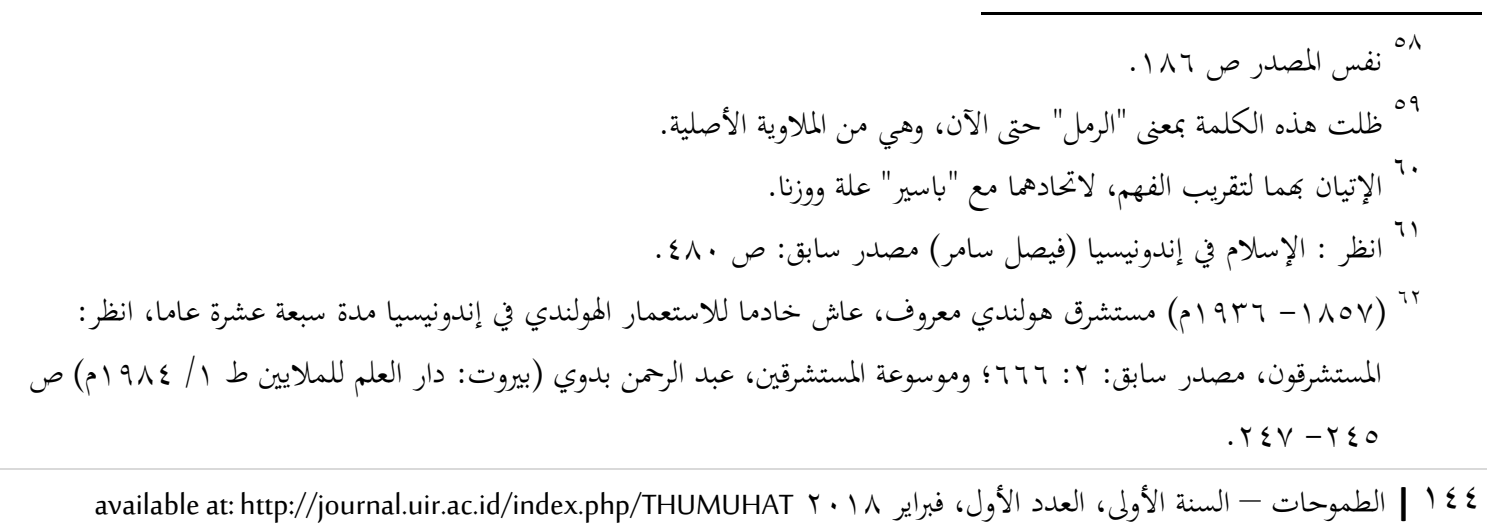


كما ورد في 》دائرة المعارف الإسلامية《 التي تعد ثمرة من ثمار التعاون العلمي الدولي بين المستشرقين، ما يؤكد قول 》أرنولد《 في الصفحة نفسها ( ا ـ ع) بأن مجيء الإسلام إلى المنطقة كان من بلاد العرب مباشرة، وأنه كان في وقت مبكر، حيث ورد في الدائرة ما نصه : الوالأرجح أن التجار العرب قد حملوا معهم الإسلام إلى سومطرة في القرون الأولى

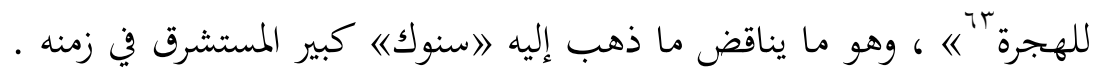
وبذلك يترجح الرأي القائل إن التجار العرب هم أول من جاء بالإسلام إلى الأرخبيل، كما ذهب إليه المؤرخون

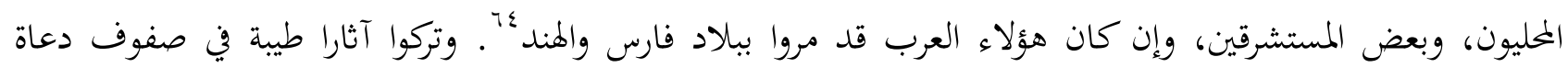
هذين البلدين الذين شاركوا مع إخوقم الدعاة العرب، وانضموا إلى قافلة الدعوة في أوقات لاحقة؛ تلبية للنداء الرباني المفهوم من النصوص بداهة. فتضافرت جهود الدعوة، مع فضل الأسبقية للدعاة العرب الأولين، ولغيرهم حسن الاقتداء بالأسوة الحسنة، ولمن بعدهم - من العلماء العاملين والدعاة - حسن الحفاظ والمتابعة. فازداد الدعوة الإسلامية انطلاقا ونشاطا، وتكاثر الداخلون في رحاب الإسلام طوعا واختيارا. وبعد، فخلاصة القول في تاريخ دخول الإسلام إلى الربوع الإندونيسية، أن جل أقوال الغربيين معتمدة على رواية 》اراركو بولو《، وأهم كتبوا في هذا الموضوع متأثرين بمعاملة الاستعمار لمستعمراته، ولم يتمكن المسلمون في الأرخبيل من دراسة هذا التاريخ إلا بعد استقلال البلاد، فلما درسوه بموضوعية وجدية، اكتشفوا الشواهد والأمارات التي جعلت حجة الغربين ومن ذهب مذهبهم واهية، وإضافة إلى ما ذكر فإن هناك حقائق تاريخية كثيرة حرفها أو دسها الكتاب الغربيين،

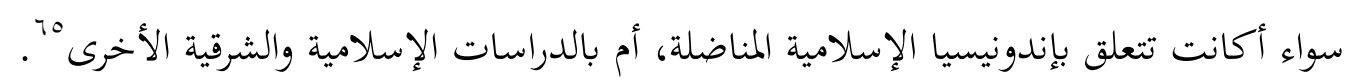
وإذا كان عدم دراسة المؤرخين والخبراء المحليين هذا التاريخ (تاريخ دخول الإسلام إلى المنطقة) دراسة وافية، قد عد في السابق من أهم دواعي حدوث الخلاف حوله بين المستشرقين ومسلمي الأرخبيل "7، فإن طريقة التفكير الموضوعية ترفض الآن هذا الاختلاف؛ لما تقدم ذكره من الجهود التي بذلت في دراسة هذا التاريخ من قبل أبناء الأرخبيل مؤرخين وعلماء، حيث عقدوا - كما سبقت الإشارة إليه - حتى سنة 911 ام أربع ندوات، كما أفم قد كتبوا عن دخول

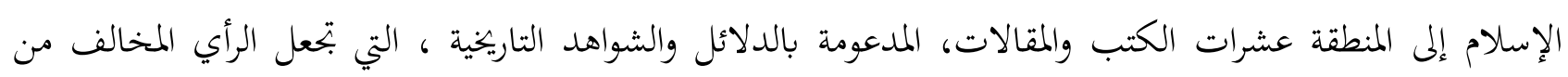
ضعيف الأقوال.

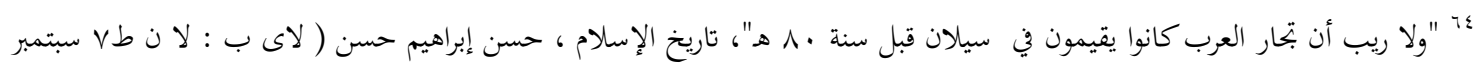
.rIT: t ( $197 \varepsilon$ "7 أوضح دليل على ذلك ما تحويه "دائرة المعارف الإسلامية" من أخطاء علمية فاحشة. انظر - مثلا - : المساجلات والمعارك الأدبية،

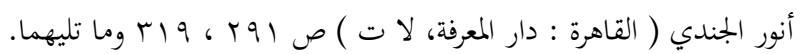

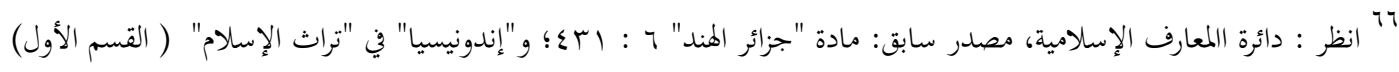


وبذلك يكون الأسلوب الأوربي الذي تناول هذا الموضوع غير مقبول في نظري، ولا ينبغي أن يكون مقبولا

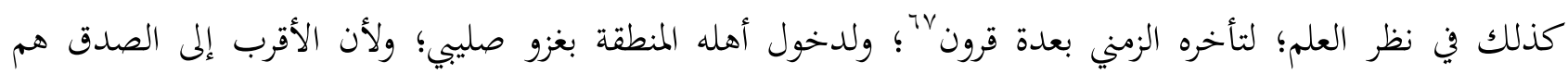

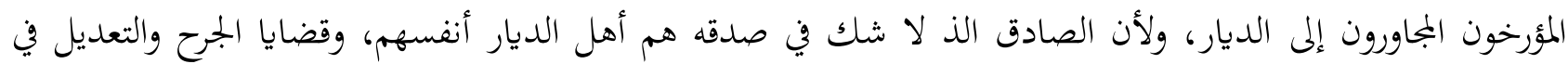

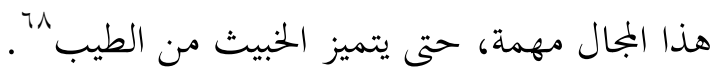
عوامل انتشار الإسلام إن الدعاة الأولين بصفتهم من القرن النبوي الذي هو خير القرونج"، كانوا شديد الاعتصام بحبل الله المتين، الفال

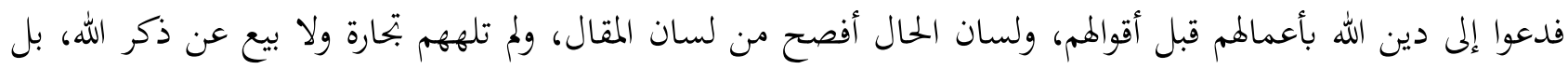

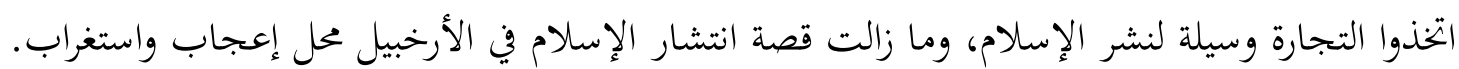

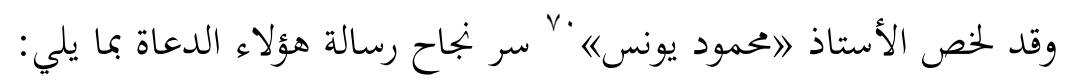

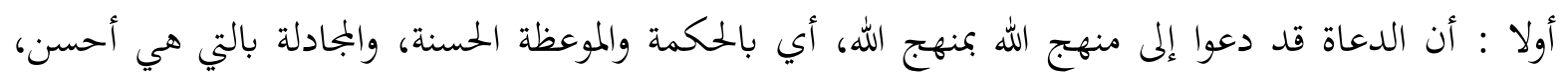

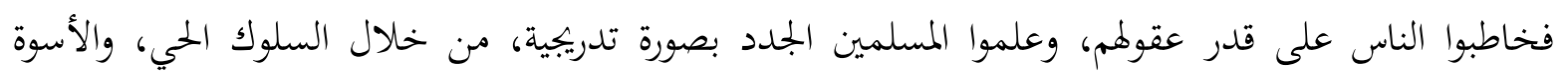
الحسنة، والعلاقة الاجتماعية.

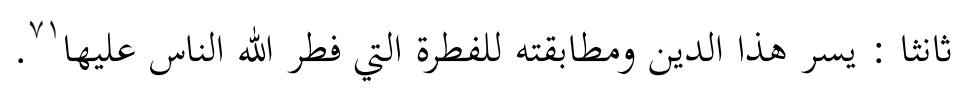

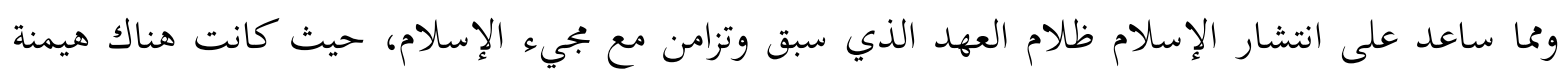

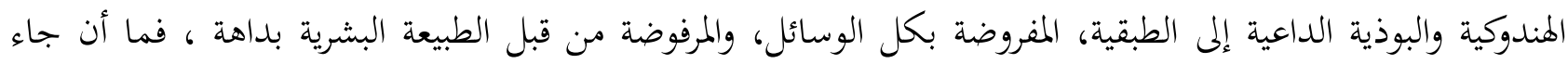

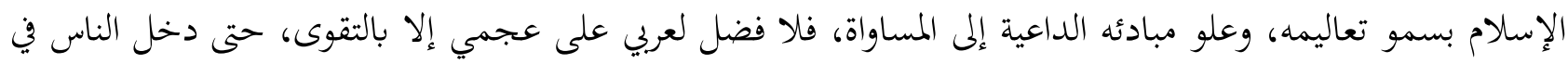
دين الله أفواجا. وخير من يوضح هذه الصورة هو الأستاذ 》اُمَّمَّ تقي الدين قنديله الذي قام بالدعوة في هذه المنطقة عشرات

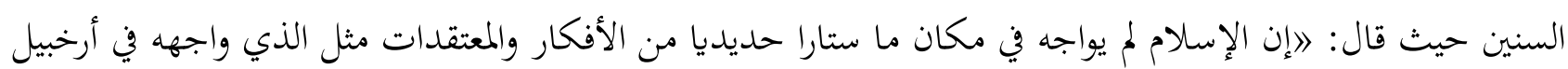

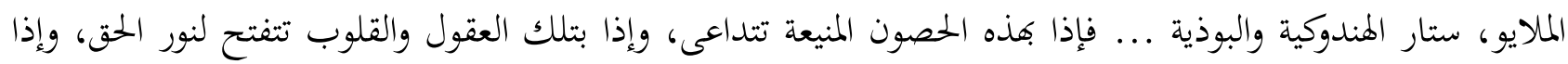

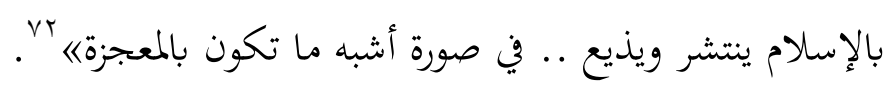

"اج يظهر أن الكاتب بقصد بذلك أن استتاجات الأوربيين حول هذا الموضوع على علاتحا، سابقة زمنا على نتائج دراسات أهل الأرخبيل بفترة طويلة، وهذه هي الحقيقة كما أشرنا إليه.

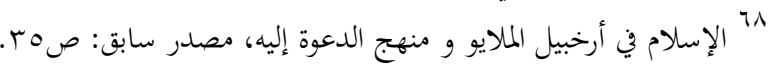

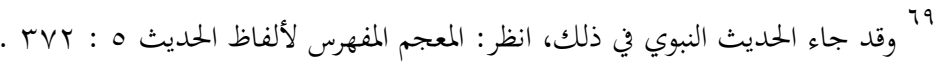

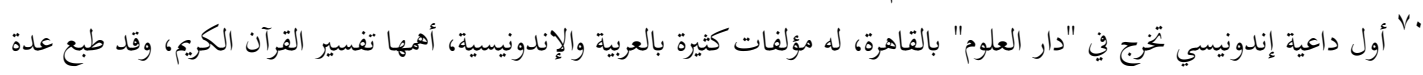
مرات حتى في إندونيسيا وفي الدول المجاورة.

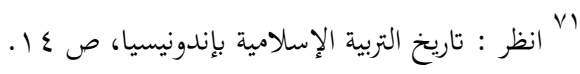

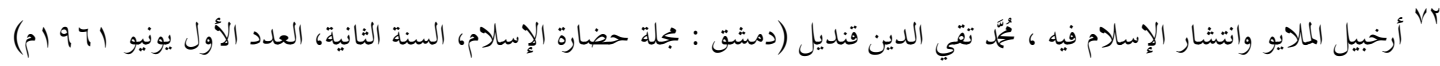

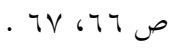

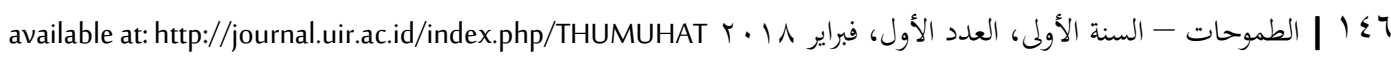


ويعد الأمراء المحليون من العوامل المساعدة على ذلك أيضا، حيث كان الناس على دين ملوكهم، وخير شاهد

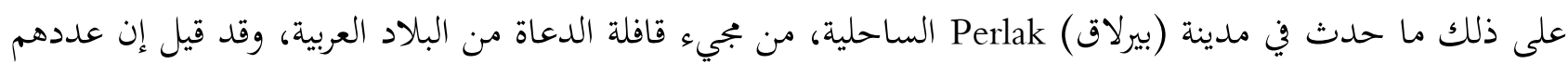

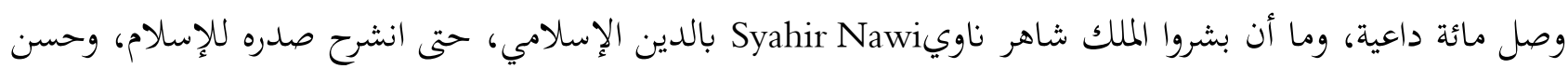

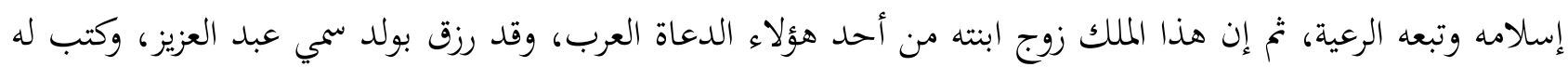

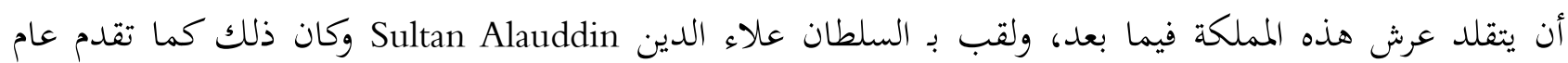

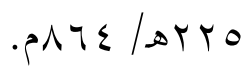

ويختلف الأسلوب الذي استخدم في تبليغ رسالة الإسلام والأسلوب الذي استختدمه المنصرون في نشر المسيحية

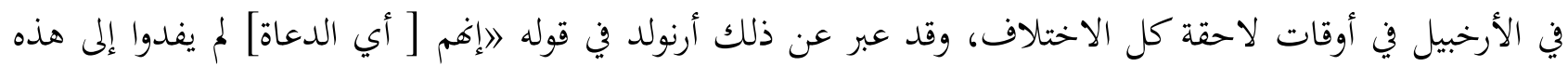

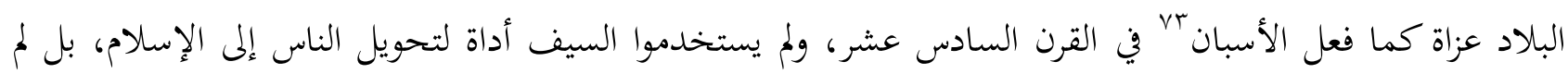

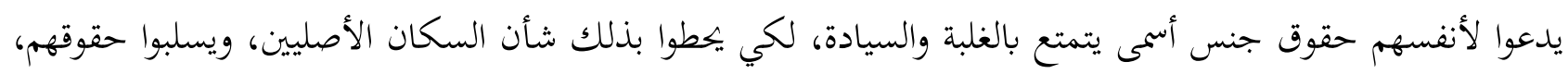

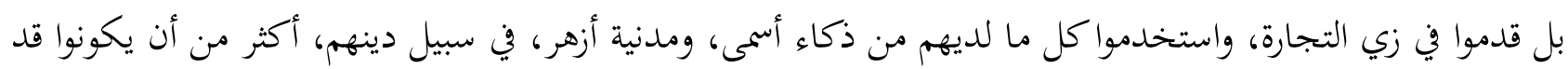

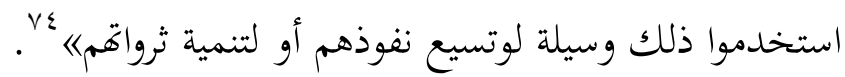

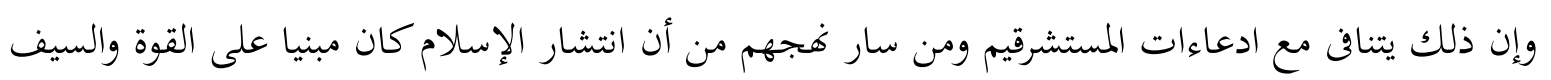
وعلى جلب الثروات المادية وغيرها V.

\section{الممالك الإسلامية}

ليس هناك - كما تقدم - أي تلازم بين دخول الإسلام إلى المنطقة، وبين قيام حكومة إسلامية، إذ مهام

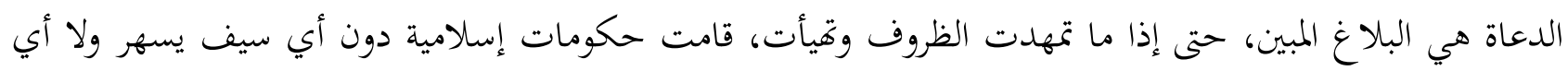
دم يهربر

وكان قيام الحكومة الإسلامية متاخرا، وذلك بقيام مملكة 》 بيرلاقه Perlak التي سجلت لها عدة إنجارات في

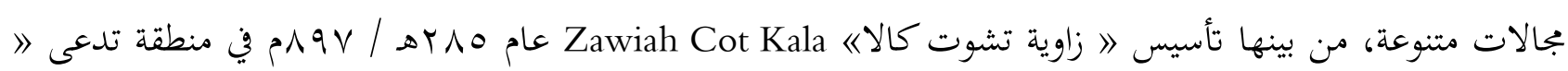

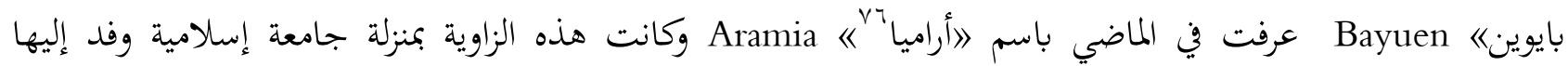

و وكذلك البرتغاليون، وعن قصة وصول البرتغاليين إلى "مليبار" وأرخبيل الملايو، انظر : تحفة المجاهدين في بعض أخبار البرتغاليين،

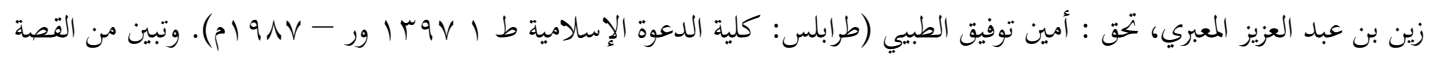

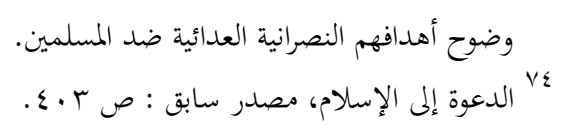

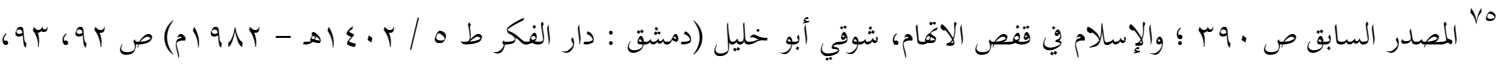

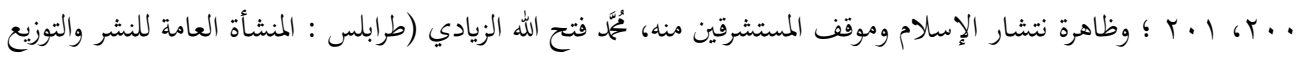

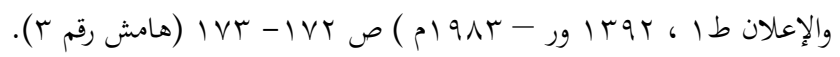

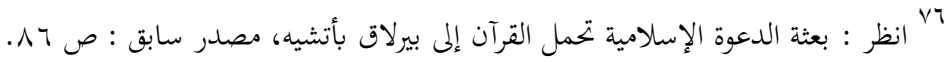

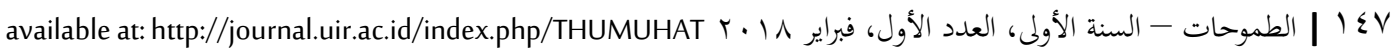


الطلاب من كل الأرجاء، وكان مؤسسها السلطان السادس مخدوم علاء الدين مُحَّم أمين عالما متبحرا. وفي مجال الاقتصاد

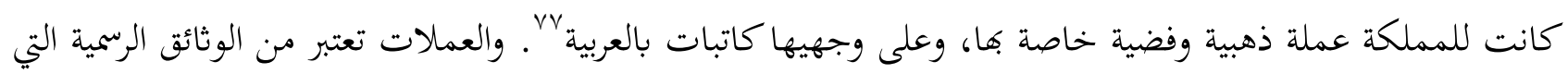

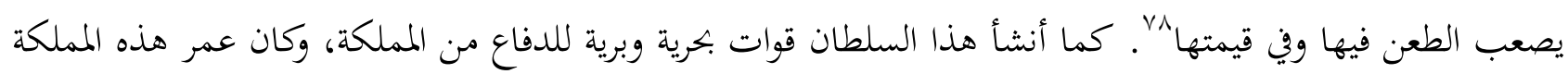
سبعا وستين وأربعمائة سنة قمرية.

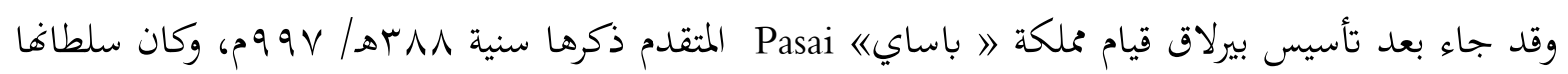
الأول الملك إبراهيم بن مخدوم الذي استمر في الحكم حتى عام ب ·عه// إ. إم، وظلت هذه المملكة قائمة لمدة ثمان

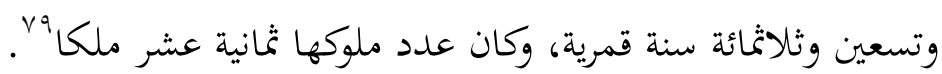
وكانت العلاقة بين مملكتي بيرلاق وباساس وطيدة، بفضل المصاهرة والتعاون الثنائي لصالح الدعوة الإسلامية، الأمر الذي أسرع بسير علمية الدعوة بالأرخبيل. وقد زار ماكوبولو - كما سبقت الإشارة إليه- هاتين المملكتين أثناء رحلته بالمنطقة، كما زار ابن بطوطة مملكة باساي في وقت لاحق.

ثم بعد سلسلة من عمليات الدعوة قامت ممالك إسلامية أخرى في مناطق متفرقة، وفي أوقات متقاربة أمثال:

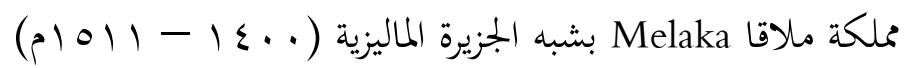

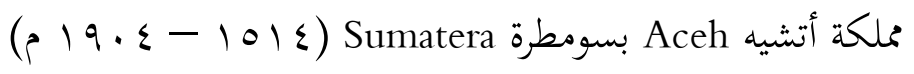
معلكة ديماك Demak لبحاوة Jawa

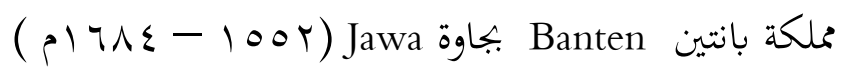

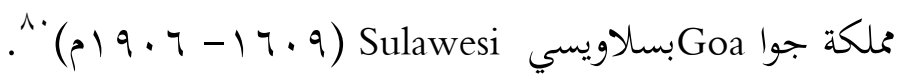
فقد توطدت أركان الإسلام بالأرخبيل الذي يعد أعظم أرخبيل في العالم، ولم تكن هناك صعوبة أو عرقلة في طريق الدعوة إلا ما قل وندر. فمثلا ظلت قبيلة باتاك' 'Batak المتمركزة بأواسط شمال سومرطرة تقاوم انتشار الإسلام زمنا طويلا حينما أسيء استخدام وسيلة الدعوة ب^، ثم بعد ما لجأ الدعاة إلى المنهج القرآي دخل الإسلام

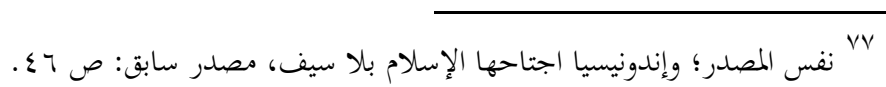

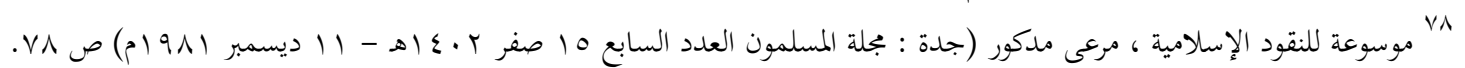

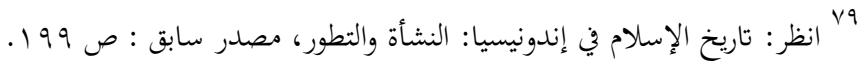

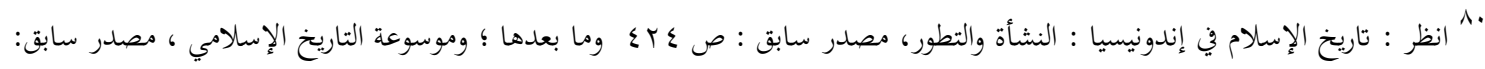

$$
\begin{aligned}
& \text { A : أظر : }
\end{aligned}
$$

^) The Progress and Arrest of Islam in Sumatera, Gottfrien Simon (London : Marshal Brother,

Ltd. 1921) 
القاصي والداني، فانقلب معارضو الإسلام إلى مساندين له بكل شجاعة وحماسة، وأصبحت طائفة من هذه القبيلة

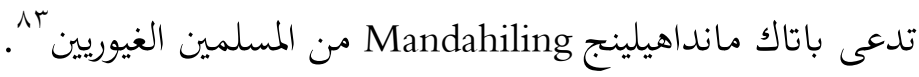
ومثال آخر جزيرة باليمBali الشهيرة التي تتركز فيها أتباع الهندوكية بعدما ضاقت بهم الأرض بما رحبت عي، فقد دخل الإسلام هذه الجزيرة أيضا وانتشر حيث بلغت نسبة المسلمين في هذه الجزيرة ما يقارب عشرة ملايين هـئ.

\section{الإسلام في عهد الاستعمار}

كانت الممالك الإسلامية - حينما وصل الاستعمار إلى الأرخبيل - منفصلة عن بعضها بسبب أو آخر؛ الأمر الذي سهل للاستعمار الغربي السيطرة عليها، وذلك لسياسته التفريقية. وكان مجيء الغربيين إلى المنطقة ذا أهداف متنوعة في مقدمتها نشر الديانة المسيحية لإخضاع العالم الإسلامي للعالم المسيحي. وقد عد الفنصو دى البركركي Alfonso

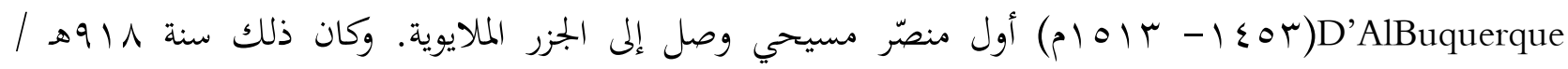

$$
\text { 11 } 11 \text { ام ب. ومن تم فإن مجيء الإسلام إلى هذه البقاع أسبق من المسيحية بقرون عديدة. }
$$

فلما أصبحت الدعوة الإسلامية تواجه الحركة التنصيرية العالمية، ظن الناس في باديء الأمر أن الإسلام سيتعرقل سيره في هذه المنعطف الجديد، وقد كان الواقع عكس ذلك، حيث ظل الإسلام ينتشر، بل كان الاستعمار من العوامل المساعدة على انتشاره، باعتراف الأعداء قبل الأصدقاء؛ ذلك أن المستعمرين كانوا يستخدمون المسلمين في مؤسساتم الاستعمارية، لأن المسلمين آناذك كانوا أحسن السكان كفاءة، وأكثرهم تقدما، ولا جرم أن الإسلام دين تقدم. وعلى عاتق المسلم عبء الدعوة بصريح النصوص؛ لكونه شهيدا على الناس، فأداء هذا الواجب المشرف هي رسالته الأولى في الحياة، فهو جزء لا يتجزأ منه، فقد مارس الموظفون المسلمون بالمؤسسات الاستعمارية الدعوة تطوعا حينما حلوا

لقد فشلت الحركة المسيحية في عهد الاستعمار في استمالة المسلمين، ما عدا بعض القبائل البدائية، وذلك مما جعل هؤلاء المسيحيين يواصلون محاولاقم التنصيرية بعد الاستقلال ^^، بل أصبحت محاولاتم في عهد الاستقلال بسب عوامل وظروف كثيرة- أشد وأبقى.

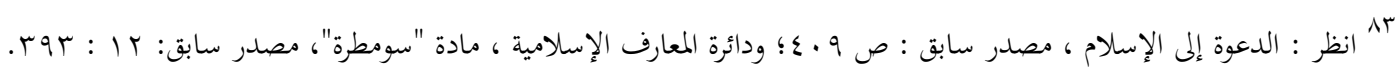

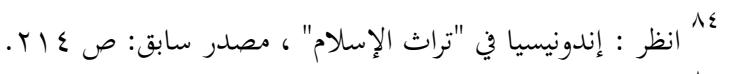

Indonesia, Department of Information, Republic of Indonesia 1985, p.103. 10

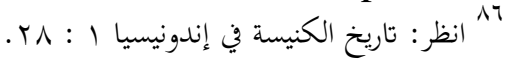

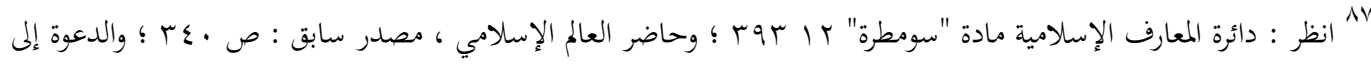

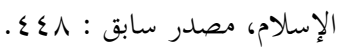

1^ كان الطيارون الأمريكيون في طليعة من بادر إلى تنظيم عمل مكثف لعملية التنصير بالمنطقة فور الاستقلال، وقد كانوا يخدمون في

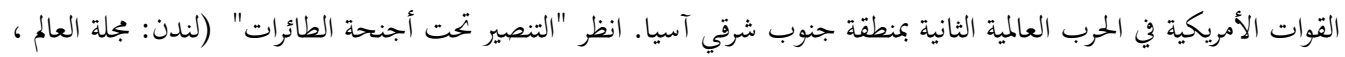

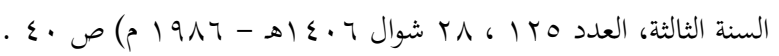




\section{المصادر والمراجع}

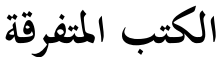

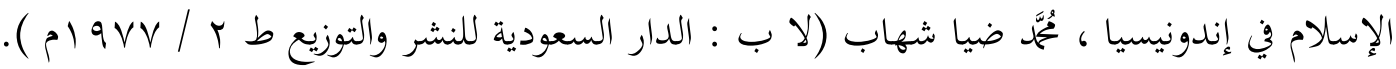

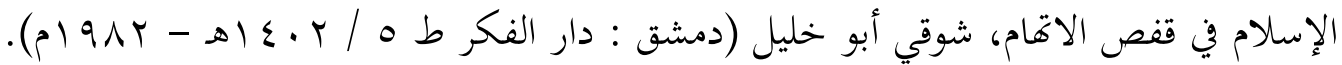

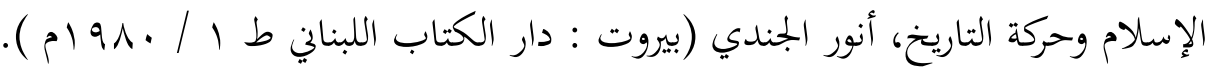
الأعلام، خير الدين الزركلي (بيروت: دار العلم للملايين ط ج ـ 9 ام ام). تاريخ الأدب الجغرافي العربي، كراتشكوفسكي، تر : صلاح عثمان هاشم (القاهرة : مطبعة لجنة التأليف والترجمة

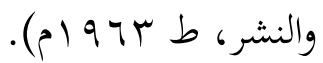

تاريخ الأدب العربي، كارل بروكلمان، تر : عبد الحليم النجار (القاهرة : دار المعارف ط ب لات )

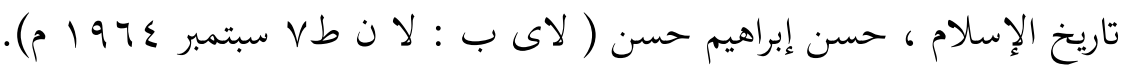

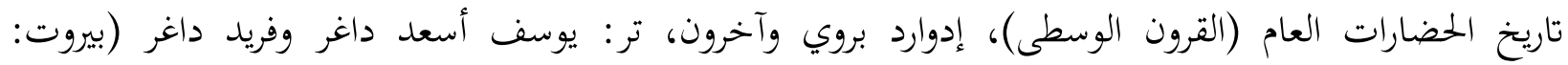

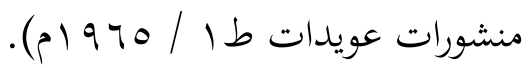

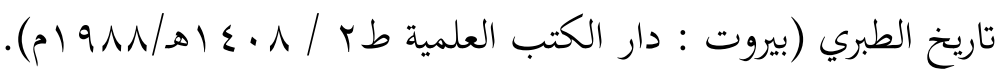
تحفة البجاهدين في بعض أخبار البرتغاليين، زين بن عبد العزيز المعبري، تحق : أمين توفيق الطبيي (طرابلس: كلية

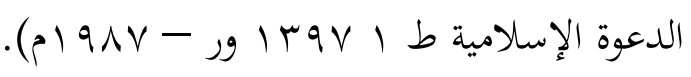
حاضر العالم الإسلامي، لوثروب ستودارد، تر: عجاج غيض (القاهرة: مطبعة عيسى البابي الحلبي وشركاؤه ط (ه) MOr

حضارة العرب، غوستاف لوبون، تر: عادل زعيتر (القاهرة: مطبعة العيسى البابي الحلبي ط 979 ام ). دائرة المعارف الإسلامية. دائرة المعارف البستاني. الدعوة إلى الإسلام، تر: حسن إبراهيم حسن وآخر (القاهرة : مكتبة النهضة المصرية ط ب / • لو ام). رحلة ابن بطوطة (بيروت: دار صادرط ع ع ع عبا اهـ ع 97 ام). ظاهرة انتشار الإسلام وموقف المستشرقين منه، تُحَّمَ فتح الله الزيادي (طرابلس : المنشأة العامة للنشر والتوزيع والإعلان

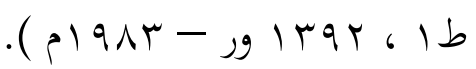

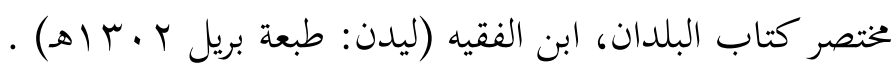

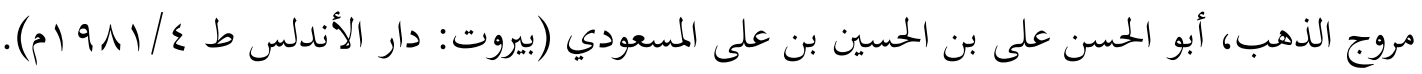

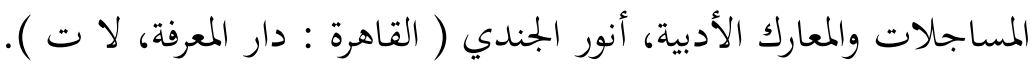




$$
\begin{aligned}
& \text { المسالك والممالك، لابن خرداذبه (بغداد: مكتبة المثني لا ط، لا ت). } \\
& \text { المستشرقون، نجيب عقيقي (القاهرة : دار المعرفة طب / } 979 \text { (م). }
\end{aligned}
$$

مسلمو ماليزيا بين الماضي والحاضر، عبد الوهاب الحاج كيا (طرابلس : كلية الدعوة الإسلامية ط ا مب9 9 (م). المصادر الجغرافية في القرن السابع الهجري، إسماعيل العربي، في كتاب (كتاب جغرافيا لابن سعد المغربي) (بيروت: المكتب التجاري للطباعة والنشر ط | / 19 | (1م). معجم البلدان، الحموي (بيروت: دار صادر $9 V V$ ام). المعجم المفهرس لألفاظ الحديث، بجموعة من المستشرقين (ليدان: مطابع بريل 970 (م).

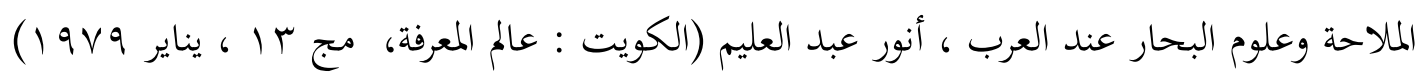
موسوعة التاريخ الإسلامي، أحمد شلبي (القاهرة: مكتبة النهضة المصرية ط / / 9 / (1م).

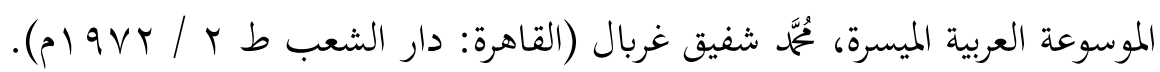

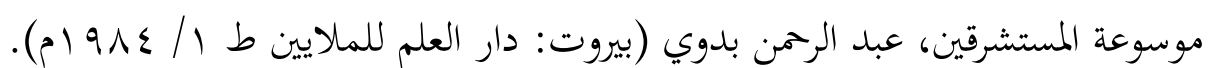
هاية الأرب، النويري (القاهرة: مطابع كوستاتسوماس وشركاه، لا ت). هدية العارفين البغدادي (استنبول : منشورات مكتبة المثنى طا / 901 (م).

باللغة الإندونيسية

ملاحظة: تستخدم لفظة ( إند ) في هامش البحث إشارة إلى أن المصدر أو المرجع مكتوب أصلا باللغة ل الإندونيسية، وفيما يلي معلومات متكاملة عن ذلك:

Ensiklopedi Indonesia, Ikhtiar Baru Van Hoeve (Jakarta : 1982). دائرة المعارف الإندونيسية

Ensiklopedi Nasional Indonesia (Jakarta : P.T. Cipta Adipustaka, 1989). دائرة المعارف الإندونيسية الوطنية

Muhammadiyah dan Kebangunan Islam di Indonesia, Solihin Salam (Djakarta :N.V Mega ND.) الخمدية والنهضة الإسلامية بإندونيسيا.

Nuruddin Arraniri, Ahmad Daudi (Jakarta : Bulan Bintang, Cet Ke-1). نور الدين الرانيري Penyebaran Agama Islam di Pulau Sumatera, Edi S. Ekadjati (Jakarta : Mutiara Sumber Widja, Cet Ke-2 1985). الدعوة الإسلامية ب(سومطرة)

Sejarah \& Keagungan Mazhab Imam Syafi'i, K.H. Sirajuddin Abbas (Jakarta : Pustaka Tarbijah, Cet. Ke-2 1972). تاريخ المذهب الشافعي وعظمته

Sejarah Kebangkiatan Islam dan Perkembangannya di Indonesia, K.H. Saifuddin Zuhri (Bandung: PT Almaarif, 2399H - 1979M). تاريخ الإسلام في إندونيسيا : النشأة والتطور

Sejarah Pendidikan Islam di Indonesia, Mahmud Yunus (Jakarta: Mutiara, Cet. Ke-2, 1979). تاريخ الإمونيخ التربية الإسلامية بإندونيسيا

Sejarah Umat Islam, Hamka (Kuala Lumpur: Pustaka Antara, 1977). تاريخ الأمة الإسلامية الإنليسية 
Sejarah Untuk SMP, Soeroto (Jakarta : Mutiara 1079). تاريخ (المقرر) لطلاب الإعدادية

$$
\begin{aligned}
& \text { مجلة كلية الدعوة الإسلامية (طرابلس: ليبيا) العدد ه سنة } 1 \text { (9 ام). }
\end{aligned}
$$

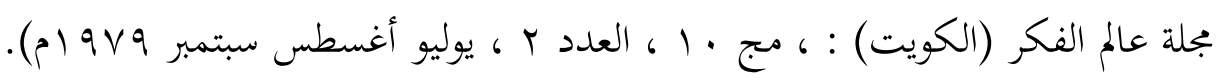

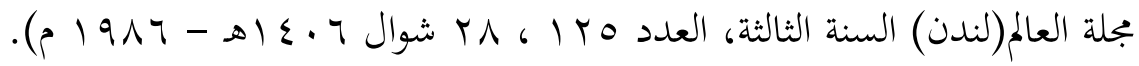

$$
\begin{aligned}
& \text { بجلة الهداية الإسلامية (القاهرة) مج ه ، جـ · 1 ، ربيع الأول بهم ا هـ). }
\end{aligned}
$$

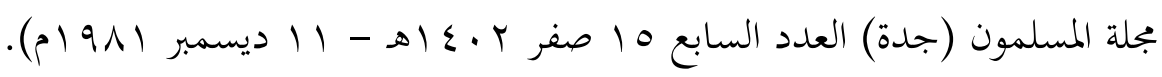

$$
\begin{aligned}
& \text { مجلة حضارة الإسلام (دمشق) السنة الثانية، العدد الأول يونيو (لب } 9 \text { (م). }
\end{aligned}
$$

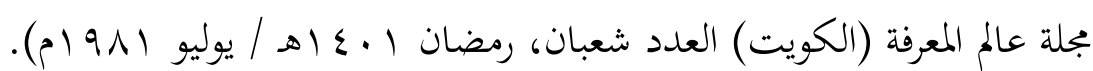

Encyclopedia of Religion and Ethics, James Hasting (London: 1947).

Indonesia, Departement of Information, Republic of Indonesia 1985.

The Progress and Arrest of Islam in Sumatera, Gottfrien Simon (London : Marshal Brother, Ltd. 1921). 